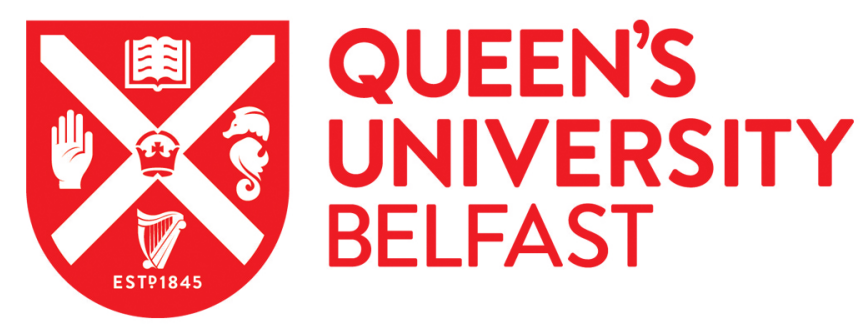

\title{
Clinical Positioning of the IAP Antagonist Tolinapant (ASTX660) in Colorectal Cancer
}

Crawford, N., Stott, K. J., Sessler, T., McCann, C., McDaid, W., Lees, A., Latimer, C., Fox, J. P., Munck, J. M., Smyth, T., Shah, A., Martins, V., Lawler, M., Dunne, P. D., Kerr, E. M., McDade, S. S., Coyle, V. M., \& Longley, D. B. (2021). Clinical Positioning of the IAP Antagonist Tolinapant (ASTX660) in Colorectal Cancer. Molecular Cancer Therapeutics, 20(9), 1627-1639. https://doi.org/10.1158/1535-7163.MCT-20-1050

Published in:

Molecular Cancer Therapeutics

Document Version:

Publisher's PDF, also known as Version of record

Queen's University Belfast - Research Portal:

Link to publication record in Queen's University Belfast Research Portal

\section{Publisher rights}

Copyright 2021 The Authors; Published by the American Association for Cancer Research.

This is an open access article published under a Creative Commons Attribution-NonCommercial-NoDerivs License

(https://creativecommons.org/licenses/by-nc-nd/4.0/), which permits distribution and reproduction for non-commercial purposes, provided the author and source are cited

\section{General rights}

Copyright for the publications made accessible via the Queen's University Belfast Research Portal is retained by the author(s) and / or other copyright owners and it is a condition of accessing these publications that users recognise and abide by the legal requirements associated with these rights.

Take down policy

The Research Portal is Queen's institutional repository that provides access to Queen's research output. Every effort has been made to ensure that content in the Research Portal does not infringe any person's rights, or applicable UK laws. If you discover content in the Research Portal that you believe breaches copyright or violates any law, please contact openaccess@qub.ac.uk. 


\title{
Clinical Positioning of the IAP Antagonist Tolinapant (ASTX660) in Colorectal Cancer
}

\author{
Nyree Crawford', Katie J. Stott', Tamas Sessler', Christopher McCann', William McDaid', Andrea Lees', \\ Cheryl Latimer', Jennifer P. Fox', Joanne M. Munck², Tomoko Smyth², Alpesh Shah'², Vanessa Martins², \\ Mark Lawler', Philip D. Dunne', Emma M Kerr', Simon S. McDade', Vicky M. Coyle', and Daniel B. Longley ${ }^{1}$
}

\section{ABSTRACT}

Inhibitors of apoptosis proteins (IAPs) are intracellular proteins, with important roles in regulating cell death, inflammation, and immunity. Here, we examined the clinical and therapeutic relevance of IAPs in colorectal cancer. We found that elevated expression of cIAP1 and cIAP2 (but not XIAP) significantly correlated with poor prognosis in patients with microsatellite stable (MSS) stage III colorectal cancer treated with 5-fluorouracil (5FU)-based adjuvant chemotherapy, suggesting their involvement in promoting chemoresistance. A novel IAP antagonist tolinapant (ASTX660) potently and rapidly downregulated cIAP1 in colorectal cancer models, demonstrating its robust on-target efficacy. In cells co-cultured with TNF $\alpha$ to mimic an inflammatory tumor microenvironment, tolinapant induced caspase-8-dependent apoptosis in colorectal cancer cell line models; however, the extent of apoptosis was limited because of inhibition by the caspase- 8 paralogs FLIP and, unexpectedly, caspase-10. Importantly,

\section{Introduction}

Colorectal cancer is the second leading cause of cancer-related deaths in the Western world. In stage IV metastatic disease, 5-year and 10 -year overall survival (OS) rates are $<6 \%$ and $<1 \%$, respectively (1). Fluoropyrimidine-based chemotherapy is the mainstay of standard-of-care (SoC) treatment for colorectal cancer in both early and advanced disease. However in early-stage disease, the benefit of fluoropyrimidine monotherapy is limited, with OS gains of less than $5 \%$ and $10 \%$ to $15 \%$ reported for stage II and III disease, respectively, with a small additional survival gain for use in combination with oxaliplatin $(2,3)$. Improved approaches are therefore urgently needed not only for the treatment of advanced colorectal cancer, but also in the adjuvant disease setting for patients who are destined to relapse but whose disease is resistant to SoC chemotherapy.

Cancer cells are frequently "addicted" to a small number of antiapoptotic proteins that are necessary for their survival. These include

\footnotetext{
'Patrick G Johnston Centre for Cancer Research, Queen's University Belfast, Belfast, Northern Ireland, United Kingdom. ${ }^{2}$ Astex Pharmaceuticals, Cambridge, United Kingdom.
}

Note: Supplementary data for this article are available at Molecular Cancer Therapeutics Online (http://mct.aacrjournals.org/).

Corresponding Author: Daniel B. Longley, Patrick G. Johnston Centre for Cancer Research, Queen's University Belfast, 97 Lisburn Road, Belfast, Northern Ireland BT9 7AE, United Kingdom. Phone: 44289097 2647; E-mail: d.longley@qub.ac.uk

Mol Cancer Ther 2021;XX:XX-XX

doi: 10.1158/1535-7163.MCT-20-1050

This open access article is distributed under Creative Commons AttributionNonCommercial-NoDerivatives License 4.0 International (CC BY-NC-ND).

(C)2021 The Authors; Published by the American Association for Cancer Research tolinapant-induced apoptosis was augmented by FOLFOX in human colorectal cancer and murine organoid models in vitro and in vivo, due (at least in part) to FOLFOX-induced downregulation of class I histone deacetylases (HDAC), leading to acetylation of the FLIP-binding partner Ku70 and downregulation of FLIP. Moreover, the effects of FOLFOX could be phenocopied using the clinically relevant class I HDAC inhibitor, entinostat, which also induced acetylation of Ku70 and FLIP downregulation. Further analyses revealed that caspase- 8 knockout RIPK3-positive colorectal cancer models were sensitive to tolinapant-induced necroptosis, an effect that could be exploited in caspase-8-proficient models using the clinically relevant caspase inhibitor emricasan. Our study provides evidence for immediate clinical exploration of tolinapant in combination with FOLFOX in poor prognosis MSS colorectal cancer with elevated cIAP $1 / 2$ expression.

the inhibitor of apoptosis proteins (IAPs), cIAP1, cIAP2, and XIAP. XIAP directly binds to, and inhibits the activation of, caspases-3, -7 , and -9 (4). cIAP1 and cIAP2 act as E3 ubiquitin ligases at complex I, which is formed following binding of the proinflammatory cytokine, TNF $\alpha$, to TNF receptor 1 (TNFR1). cIAP1 and cIAP2 polyubiquitinate RIPK1 resulting in the activation of the canonical NFKB signaling pathway, which in turn results in the transcription of antiapoptotic proteins, including cIAP1, cIAP2 and inflammatory cytokines (including TNF $\alpha$ itself) in a prosurvival/inflammatory feedforward loop (5). Complex I dissociates following deubiquitination of RIPK1 to form the death-inducing platform, complex IIa composed of FADD, RIPK1, TRADD, and procaspase-8 (6). In the absence of cIAPs, RIPK1 is not polyubiquitinated, and the cell death inducing platform complex IIb (containing of FADD, RIPK1, and caspase-8) is formed, which can also activate cell death. Hence targeting IAPs have potential to both activate cell death and inhibit antiapoptotic and proinflammatory signaling.

Multiple IAP antagonists, based on the endogenous inhibitor SMAC (second mitochondrial activator of caspases), have been developed and several of these are currently under early-phase clinical evaluation including LCL-161, Xevinapant (Debio 1143), Birinapant (TL32711), APG-1387, and tolinapant (ASTX660). Xevinapant is the most clinically advanced IAP antagonist, currently being evaluated in a phase III combination trial with platinum-based chemoradiotherapy in high-risk head and neck squamous cell carcinoma (NCT04459715), following promising results in a phase II trial (7). Xevinapant is also under investigation in combination with the immune checkpoint inhibitor pembrolizumab in multiple cancers, including a specific metastatic colorectal cancer cohort (NCT03871959). Although the majority of these IAP antagonists have inherent selectivity for cIAP1 over XIAP, others, including APG-1387 and tolinapant (ASTX660) target cIAP1/2 and XIAP. 
Tolinapant (Astex Pharmaceuticals) is a novel, non-peptidomimetic IAP antagonist with balanced nanomolar potency against cIAP $1 / 2$ and XIAP that was discovered utilizing fragment-based drug design (8). The first-in-human phase I trial of tolinapant indicated a manageable safety profile and had evidence of clinical activity; phase II studies are ongoing (9).

In this study, we assessed the activity of tolinapant in preclinical models of colorectal cancer as a single agent and in combination with both SoC chemotherapeutics and novel therapies rationally selected on the basis of mechanistic insights.

\section{Materials and Methods}

\section{Data analysis}

The microsatellite stable (MSS) stage III treated colorectal cancer patient cohort was extracted from the GSE39582 (10) datasets, from the National Center for Biotechnology Information Gene Expression Omnibus, and the expression matrix was processed by collapsing to one probeset per gene using MaxMean from the WGCNA package (11). The IAP mRNA levels were normally distributed, high and low level of expression was determined using a median split. KaplanMeier estimators and Cox proportional hazards regression analysis were assessed using the survival and survminer R packages. Tumor cell type profiling based on gene signature method has been performed by xCELL (12). The single-sample gene set enrichment analysis (ssGSEA) method was implemented through GenePattern web tool (13) using the Hallmark gene set molecular signature (14). Heatmaps were generated after mean z-score normalization. Gene level cell line expression values were assessed from Cancer Cell Line Encyclopedia, curated by the Broad Institute (15).

\section{Compounds}

Tolinapant was obtained from Astex Pharmaceuticals. Entinostat, necrosulfonamide, and emricasan (IDN-6556) were supplied by Selleckchem. Z-VAD-fmk was purchased from Calbiochem. TNF $\alpha$ was supplied by Prospec. 5-Fluorouracil (5FU) and oxaliplatin were obtained from Belfast City Hospital Pharmacy (Belfast, NI).

\section{In vitro models}

LoVo, HCT116, DLD-1, SW620, and HT29 cells were purchased as authenticated stocks from ATCC, and frozen stocks were immediately established from early passage cells. Cell lines were cultured for no more than 20 passages following thawing. All cell lines were screened every month for Mycoplasma using MycoAlert Mycoplasma Detection Kit (Lonza). HT29 and LoVo cells were maintained in DMEM (Invitrogen) supplemented with 10\% FBS (Invitrogen). HCT116 and SW620 cells were maintained in McCoys 5A medium (Invitrogen) supplemented with $10 \%$ FBS (Invitrogen). DLD-1 cells were maintained in RPMI medium (Invitrogen) supplemented with 10\% FBS (Invitrogen).

VillinCre ${ }^{\mathrm{ER}} ; A p c^{\mathrm{f} / / \mathrm{fl}} ; \operatorname{Kras}^{\mathrm{G} 12 \mathrm{D} /+} ; \operatorname{Tr} p 53^{\mathrm{f} / \mathrm{fl}}$ (AKP) and VillinCre ${ }^{\mathrm{ER}}$; $A p c^{\mathrm{f} / \mathrm{fl}} ; \mathrm{Kras}^{\mathrm{G} 12 \mathrm{D} /+}(\mathrm{AK})$ organoids were generated from genetically engineered mouse models as described previously $(16,17)$. Organoids were cultured in ADF complete media: Advanced DMEM/F12 media (Invitrogen), supplemented with $10 \mathrm{mmol} / \mathrm{L}$ HEPES (Sigma), $2 \mathrm{nmol} / \mathrm{L}$ L-Glutamine (Invitrogen), N2 supplement (Invitrogen), B27 supplement (Invitrogen), $50 \mathrm{ng} / \mathrm{mL}$ recombinant human EGF (Peprotech), and $100 \mathrm{ng} / \mathrm{mL}$ recombinant murine Noggin (Peprotech). Organoids were harvested in cell recovery solution (Corning), washed with PBS and resuspended in 1:1 ratio Matrigel (Corning):Media and cultured in complete media.

\section{Measuring diameter of organoids}

Organoids were cultured and treated as detailed. Pictures of the organoids were taken with an EVOS XL core cell imaging system (Thermo Fisher Scientific) with $10 \mathrm{x}$ magnification. Diameter of organoids, in arbitrary units (AU), were determined utilizing ImageJ software.

\section{Cell line screen}

A total of 36 cell line screen was carried out by Chempartner. Each cell line was tested once in duplicate following incubation with 10 different concentration of tolinapant $(0.0005-10 \mu \mathrm{mol} / \mathrm{L})$ alone and in combination with TNF $\alpha(1 \mathrm{ng} / \mathrm{mL})$ for 72 hours. Cell viability was assessed by CellTitreGlo.

\section{Western blotting}

Western Blotting was carried out as described previously (18). Mcl1 (No. 4572S), XIAP (No. 2042S), BAX (No. 5023S), SMAC (No. 2954), RIPK1 (No. 3493), RIPK3 (No. 13526), MLKL (No. 14993), acetylated lysine (No. 9441L), pMLKL (Ser358; No. 91689), pRIPK3 (Ser227; No. 93654), pRIPK1 (Ser166; No. 65746), and PARP (No. 9542) antibodies were purchased from Cell Signaling Technology. Murine RIP3 (No. 95702S) and pRIP3 (Thr231/Ser232; No. 91702S) were also purchased from Cell Signaling Technology. cIAP1 (No. ALX-803-335-C100), cIAP2 (No. ALX-803-341-C100), and caspase-8 (No. ALX-804-242-C100) antibodies were purchased from Enzo. FLIP (No. AG-20B-0056-C100) antibody was from AdipoGen and hyperacetylated H4 (No. 06-946) was from Millipore. FADD (No. 556402) antibody was purchased from BD Biosciences, caspase-10 (No. M0593) from MBL, Ku70 (No. Sc-17789) from Santa Cruz Biotechnology, and $\beta$-actin (No. A5316) from Sigma.

\section{siRNA transfections}

ON-TARGET plus SMART pool Murine cFLIP siRNA and SCR, cFLIP(L), cFLIP(S), cFLIP(T) and caspase-10 siRNA's was purchased from Dharmacon. siRNA transfections were carried out with Lipofectamine RNAiMAX (Invitrogen) transfection reagent according to the manufacturer's instructions. siRNA sequences: SCR: UUCUCCGAACGUGUCACGU, FLIP(L): AACAGGAACTGCCTCTACTT, FLIP(S): AAGGAACAGCTTGGCGCTCAA, FLIP(T): AAGCAGTCTGTTCAAGGAGCA. Ku70 siRNA transfections were carried out as described previously (19).

\section{Quantitative PCR}

RNA was extracted using High Pure RNA Isolation kit (Roche) according to the manufacturer's instructions. cDNA was synthesized using Transcriptor First Strand cDNA synthesis kit (Roche) according to the manufacturer's instructions. qPCR was carried out using Syber green on LC480 light cycler (Roche) according to the manufacturer's instructions. Primer sequences: cFLIP(L): F:CCTAGGAATCTGCCTGATAATCGA, R:TGGGATATACCATGCATACTGAGATG, FLIP(S): F: ATTTCCAAGAATTTTCAGATCAGGA, R:GCAGCAATCCAAAAGAGTCTCA, 18S: F:GTAACCCGTTGAACCCCATT, R: CCATCCAATCGGTAGTAGCG, RIPK3: GCCTCCACAGCCAGTGAC, TCGGTTGGCAACTCAACTT, Murine cFLIP: F:GCAGAAGCTCTCCCAGCA, R:TTTGTCCATGAGTTCAACGTG, Murine 18S: F:GCAATTATTCCCCATGAACG, R:GGGACTTAATCAACGCAAGC.

\section{Cell line generation}

HCT116 cells overexpressing cFLIP(S) or cFLIP(L) were generated as described previously (18). HCT116, DLD1, LoVo, HT29, and SW620 caspase-8 CRISPR cell lines were generated by retroviral infection with 
pLentiCRISPR with guideRNA AAGTGAGCAGATCAGAATTG, a kind gift from Galit Lahav. HCT116 and HT29 FADD CRISPR cell lines were generated by retroviral infection with pLentiCRISPR with guideRNA GCGGCGCGTCGACGACTTCG. Cells were clonally selected for complete knockdown by Western blot analysis. HCT116 Caspase10 CRISPR cell lines were generated as described previously (20).

\section{Immunoprecipitations}

Caspase- 8 and acetylated lysine immunoprecipitations were carried out as described previously $(18,19)$.

\section{Cell surface flow cytometry}

TNFR1 cell surface staining was carried out a described previously (18).

\section{Cell viability assay}

Two-dimensional cell viability was assessed using CellTiter-Glo Luminescent Assay (Promega) according to the manufacturer's instructions. Three-dimensional (3D) cell viability was determined with CellTitre-Glo 3D Cell Viability Assay (Promega), according to the manufacturer's instructions.

\section{Annexin V/propidium iodide staining}

FITC-tagged Annexin V (BD Biosciences), propidium iodide (PI; Sigma), and Hoechst stain (Invitrogen) were used to assess cell death. Annexin V/PI staining was assessed by high content microscopy on an Array Scan XTI microscope (Thermo Fisher Scientific).

\section{In vivo experiments}

A total of $2 \times 10^{6}$ HCT116, HT29, and DLD- 1 cells in PBS:Matrigel (Corning) suspension were implanted single flank into 8- to 10-week-old male BALB/c nude mice. When tumors of approximately $100 \mathrm{~mm}^{3}$ were established, mice were randomized and treated with vehicle and tolinapant. Tolinapant was administered orally with $\mathrm{H}_{2} \mathrm{O}$ as a vehicle daily, 1 week on, 1 week off, and 1 week on. A total of 50 AKP organoids in PBS:Matrigel (Corning) suspension were subcutaneously injected into C57BL-6J mice and treatment started when average tumor size approximately $150 \mathrm{~mm}^{3}$. Mice were treated with $10 \mathrm{mg} / \mathrm{kg} 5 \mathrm{FU}$ (vehicle:PBS) and $1 \mathrm{mg} / \mathrm{kg}$ oxaliplatin (vehicle: $\mathrm{H}_{2} \mathrm{O}$ ) intraperitoneally and $16 \mathrm{mg} / \mathrm{kg}$ tolinapant (vehicle: $\mathrm{H}_{2} \mathrm{O}$ ) orally. Mice were treated for 3 weeks: once a week with oxaliplatin, daily with $5 \mathrm{FU}$, and tolinapant daily with a 1 week on, 1 week off, and 1 week on schedule. All procedures were carried out in accordance with the Animals (Scientific Procedures) Act, 1986 under project licenses PPL 2590b and PPL 2874 and maintained as described previously (21). Tumor volume was assessed using digital calipers, three times a week. Tumor volume was calculated by the following formula: shortest tumor diameter ${ }^{2} \times$ longest tumor diameter $\times 0.5$.

\section{Statistical analysis}

Results were compared using a two-tailed Student $t$ test, ${ }^{*}, P<0.05$; **, $P<0.01$; and ${ }^{* * *}, P<0.001$.

\section{Results}

Elevated cIAP1 and cIAP2 expression correlates with worse prognosis of patients with stage III MSS with colorectal cancer treated with adjuvant chemotherapy. Analysis of patients with colorectal cancer (10) revealed that elevated expression of cIAP1/BIRC2 (HR, $0.47 ; P=0.05$ ) and cIAP2/BIRC3 (HR, 0.34; $P=0.009$ ) [which are normally distributed (Supplementary Fig. S1A)], but not XIAP/XIAP correlated with worse OS in patients with stage III MSS treated with chemotherapy postsurgery (adjuvant chemotherapy; Fig. 1A; Supplementary Fig. S1B), whereas no significant association in stage III patients treated by surgery alone. Although cIAP-1 and cIAP-2 expression were significantly correlated [Pearson $r=0.47, P=1.3 \mathrm{e}(-8)$ ], not all cIAP1-high tumors were also cIAP2-high (Fig. 1C; Supplementary Fig. S1C). ssGSEA comparing cIAP1-high or cIAP2-high and -low groups identified significant enrichments for several key inflammatory signaling pathways in both the cIAP1- and cIAP2-high groups, including "TNF $\alpha$ signaling via NFKB" and other inflammatory pathways (Fig. 1B and C). Consistent with this, the tumors from the cIAP1and cIAP2-high groups were enriched for the presence of several key immune cell types, with significant enrichment of $\mathrm{CD} 4^{+}$memory $\mathrm{T}$ cells, TH2 cells, and M1-polarized macrophages in both groups (Fig. 1D and E). In addition to apoptosis signaling, there was also a significant enrichment for KRAS signaling in both the cIAP1- and cIAP2-high groups (Fig. 1B). IAP expression was not higher in KRASmutant tumors (and was not correlated with TP53 or BRAF mutations; Supplementary Fig. S1C and S1D), indicating that the correlations between cIAP1/2 expression and survival (Fig. 1A) are not due to enrichment for KRAS-mutant tumors, which have a worse, but not significantly worse prognosis in this MSS stage III cohort (Supplementary Fig. S1E).

\section{Sensitivity of colorectal cancer cell lines to tolinapant in vitro and in vivo}

The analysis of the clinical cohort suggested potential for CIAP1 and cIAP2 as therapeutic targets for improving the efficacy of SoC chemotherapy in MSS stage III disease. We therefore next assessed the cell death inducing activity of the novel IAP antagonist tolinapant by screening a panel of 36 colorectal cancer cell lines alone or in the presence of low concentrations of TNF $\alpha$ (Fig. 2A); to reflect the enrichment for TNF $\alpha$ signaling in the cIAP1/2-high groups (Fig. 1B and $\mathrm{C}$ ) and the presence of immune cells such as M1 macrophages (Fig. 1D and E), which are rich sources of TNF $\alpha$ (22). In the absence of TNF $\alpha$, tolinapant had modest growth inhibitory effects across the panel, whereas in the presence of TNF $\alpha$, a high number of cell lines exhibited significant sensitivity to tolinapant (Fig. 2A). These effects were further assessed in a subset of colorectal cancer cell line models with a range of sensitivities (Supplementary Fig. S2A), each of which expressed all the components of the TNFR1 complex II interactome and XIAP at the protein level (albeit to varying levels; Fig. 2B) as well as cell surface TNFR1 (Fig. 2C). On-target activity of tolinapant, as evidenced by degradation of cIAP1 (the pharmacodynamic biomarker for IAP antagonists), was confirmed at nM potency in all five models (Fig. 2D; Supplementary Fig. S2B); whereas cIAP2 was also downregulated (albeit to a lesser extent than cIAP1) by tolinapant in three of five models. XIAP was unaffected, consistent with the expected effects of IAP antagonists which disrupt XIAP's protein-protein interactions with caspases- $3,-7$, and -9 , but do not typically cause XIAP degradation (23). Downregulation of cIAP1 in response to tolinapant, which is a result of triggering its autoubiquitination and degradation via the proteasome (24), was found to be rapid and sustained (Supplementary Fig. S2C). Loss of IAPs has been widely reported to result in the formation of the cell death platform, complex II. In the presence of $\mathrm{TNF} \alpha$, tolinapant indeed promoted the formation of complex II as evidenced by the interaction of caspase- 8 with RIPK1; this was also detected in response to tolinapant alone in three of five models. HCT116, HT29 and LoVo cells albeit to a much lower level than in response to tolinapant/TNF $\alpha$ (Fig. 2E; Supplementary Fig. S2D).

In agreement with the cell line screen, significant cell death measured by Annexin V/PI flow cytometry, was observed in response to 
A

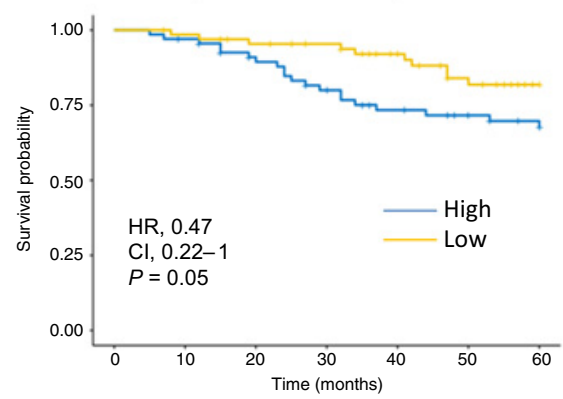

B

\begin{tabular}{|r|c|c|}
\hline sSGSEA_Cancer_Hallmarks & cIAP1/BIRC2 & cIAP2/BIRC3 \\
\hline TNFA_SIGNALING_VIA_NFKB & 0.036866 & $3.90 \mathrm{E}-10$ \\
\hline INFLAMMATORY_RESPONSE & 0.010582 & $7.55 \mathrm{E}-09$ \\
\hline IL6_JAK_STAT3_SIGNALING & n.S. & $2.15 \mathrm{E}-08$ \\
\hline INTERFERON_GAMMA_RESPONSE & 0.040849 & $2.64 \mathrm{E}-07$ \\
\hline KRAS_SIGNALING & 0.016703 & $2.23 \mathrm{E}-07$ \\
\hline KRAS_SIGNALING_UP & 0.01566 & $2.48 \mathrm{E}-07$ \\
\hline APOPTOSIS & 0.034156 & $3.56 \mathrm{E}-07$ \\
\hline
\end{tabular}

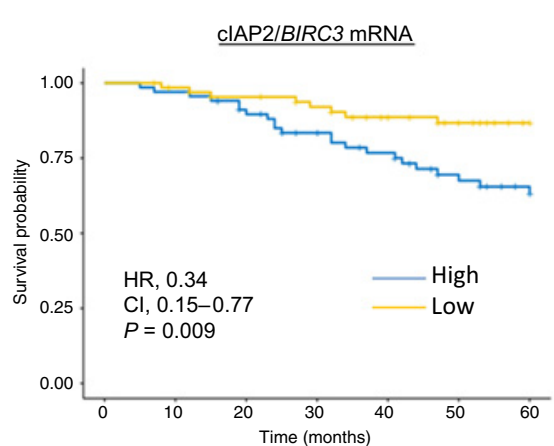

D
C

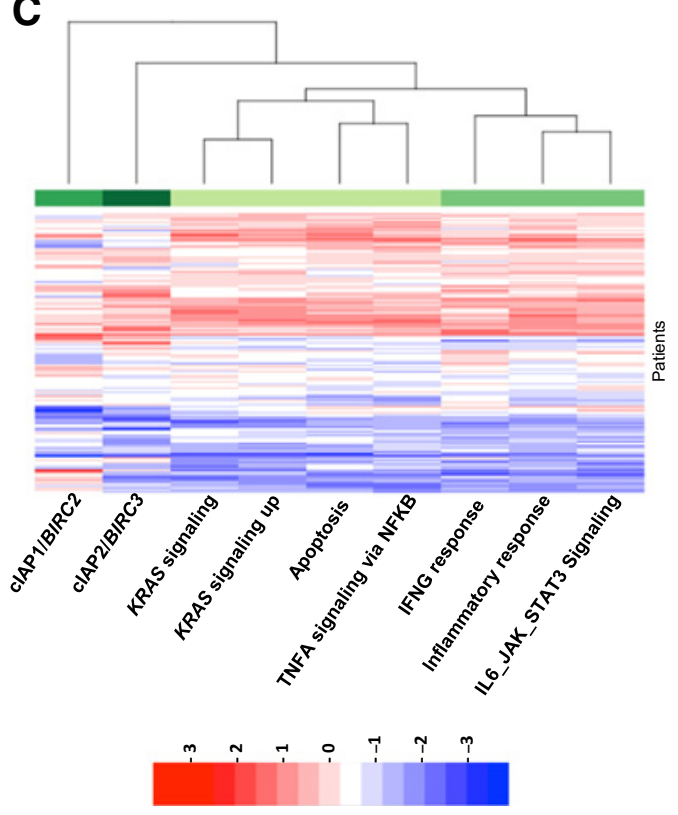

$\mathbf{E}$

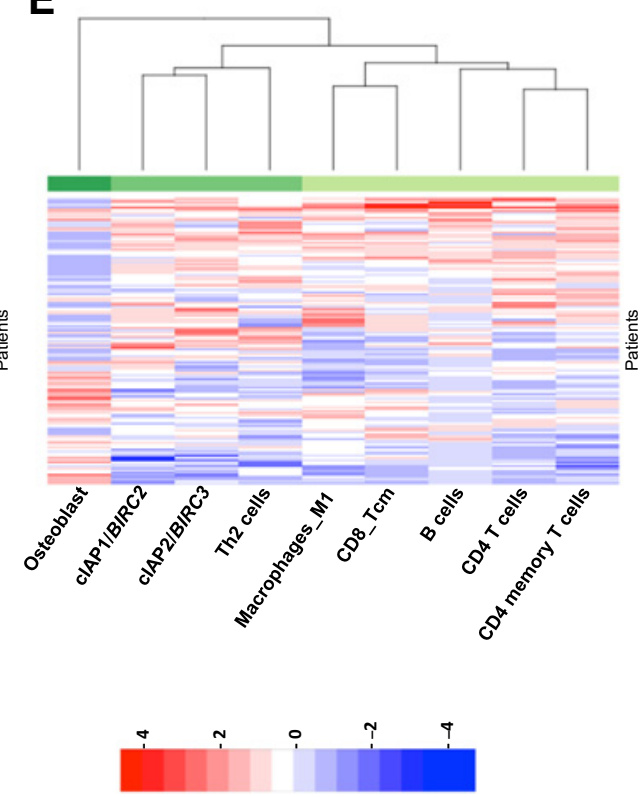

Figure 1.

Correlation between high CIAP1/2 expression and prognosis. Analysis of patients with stage III MSS who received adjuvant fluorouracil-based treatment extracted from GSE39582 cohort. A, Kaplan-Meier plots of 5-year OS. Graphs comparing the difference in survival probability based on BIRC2 and BIRC3 expression levels alone. Results are shown with the log-rank test, the HR with its $95 \%$ confidential interval and the Wald test of significance. B-E, Difference of pathway activation by ssGSEA (B) and cell type profiling (D) by XCELL between cIAP1 or cIAP2 high and low expressing patients was assessed by one-way ANOVA model. Numbers shown are the calculated $P$ values. Heatmap were drawn showing the Z-scores of the significantly different sSGSEA pathways (C) and immune or stroma infiltration by $\mathrm{XCELL} \mathrm{(E).}$

tolinapant in the presence of TNF $\alpha$ in the HCT116 model (Fig. 2F). Similar results were observed in the HT29 model, albeit the extent of cell death at 24 hours was less; however, lower levels of cell death were observed in the DLD-1 model despite complex II formation (Fig. 2E and $\mathbf{F}$ ). In the in vivo setting, we hypothesized that murine TNF $\alpha$ (as well as xenograft-derived human $\mathrm{TNF} \alpha$ ) could potentially drive complex II formation as murine TNF $\alpha$ can bind the human TNFR1. Moreover, IAP antagonists have been reported to promote production of TNF $\alpha$ by monocytic cells (25). Significant albeit limited retardations of tumor growth were observed in HCT116 and HT29 xenografts but not DLD-1, results which were in line with the relative in vitro sensitivity of these models (Fig. 2G).

\section{Tolinapant enhances sensitivity to SoC chemotherapy}

Having established the effects of tolinapant/TNF $\alpha$ combinations, we next evaluated whether the addition of tolinapant could increase sensitivity to SoC chemotherapy FOLFOX (5-fluorouracil plus oxaliplatin). Statistically significant enhancement of FOLFOX-induced 

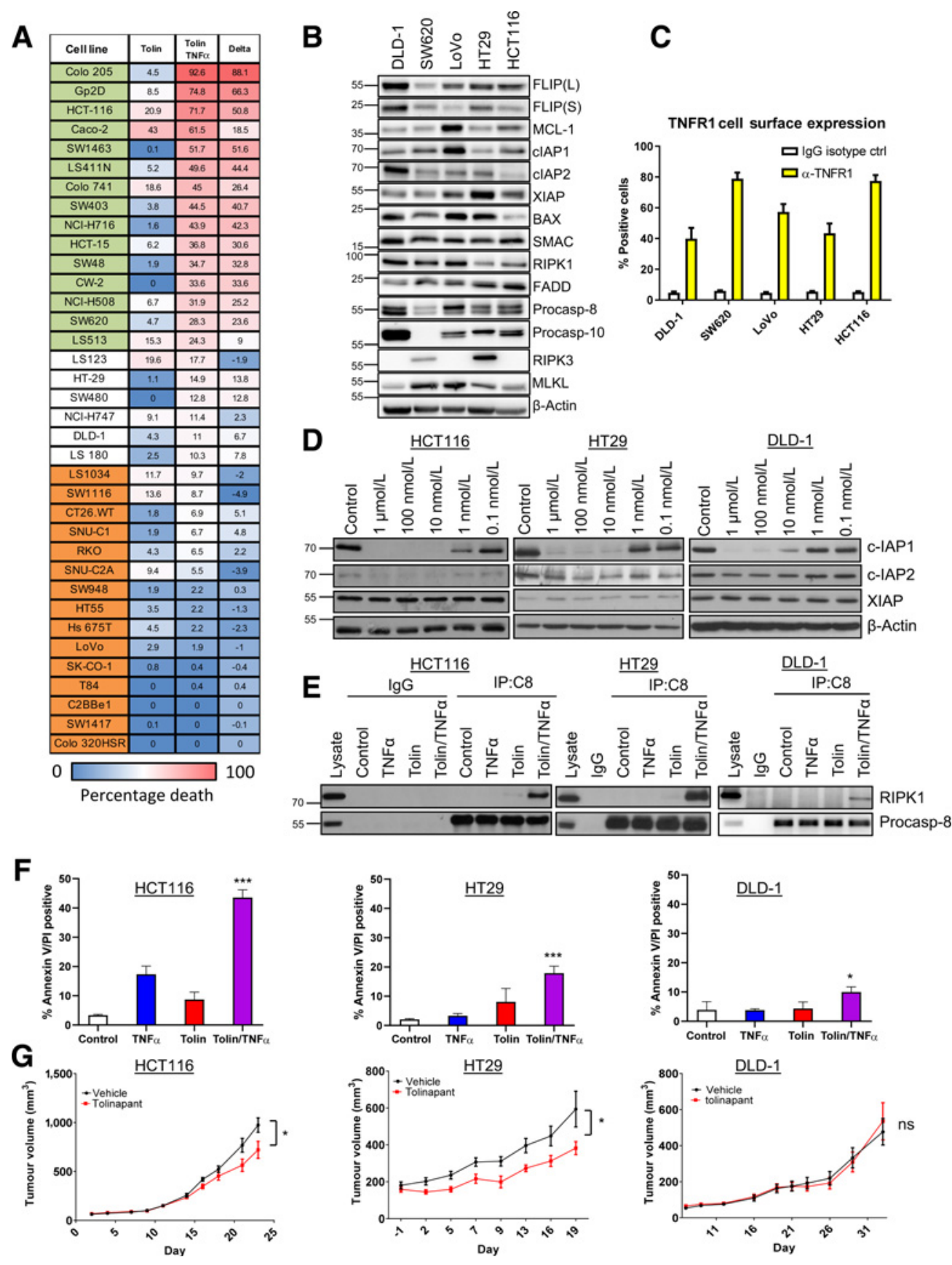

Figure 2.

Sensitivity of colorectal cancer cell lines to IAP inhibitor, tolinapant. A, Cell viability assay in 36 colorectal cancer cell line panel following 72 hours treatment with tolinapant (tolin; 10-point assay 0.0005-10 $\mu \mathrm{mol} / \mathrm{L}$ ) alone and in combination with TNF $\alpha(1 \mathrm{ng} / \mathrm{mL}$ ), represented as relative activity area (\%), calculated as (experimental AUC/max AUC possible). Cell lines categorized as sensitive to tolinapant/TNF $\alpha$ are highlighted in green, intermediate in white, and resistant in orange. B, Western blot analysis of basal expression of FLIP(L), FLIP(S), Mcl-1, CIAP1, cIAP2, XIAP, BAX, SMAC, RIPK1, FADD, procaspase-8, procaspase-10, RIPK3 and MLKL and $\beta$-actin in a panel of colorectal cancer cell lines. C, Cell surface expression of TNFR1 in DLD1, SW620, LoVo, HT29, and HCT116 cell lines, represented as \% of TNFR1positive cells compared with an IgG isotype control. D, Western blot analysis of CIAP1, CIAP2, XIAP, and $\beta$-actin in HCT116, HT29, and DLD-1 cells following treatment with $1 \mu \mathrm{mol} / \mathrm{L}, 100 \mathrm{nmol} / \mathrm{L}, 10 \mathrm{nmol} / \mathrm{L}, 1 \mathrm{nmol} / \mathrm{L}$, and $0.1 \mathrm{nmol} / \mathrm{L}$ tolinapant for 24 hours. E, Western blot analysis of RIPK1 and procaspase-8 following immunoprecipitation of caspase-8 from HCT116, HT29, and DLD-1 cells treated with $1 \mathrm{ng} / \mathrm{mL}$ TNF $\alpha, 1 \mu \mathrm{mol} / \mathrm{L}$ tolinapant and a combination of TNF $\alpha /$ tolinapant for 3 hours in the presence of $20 \mu \mathrm{mol} / \mathrm{L} z$-VAD-fmk. An IgG isotype control was used as a control. F, Annexin V/PI analysis in HCT116, HT29, and DLD-1 cells following treatment with $1 \mathrm{ng} / \mathrm{mL}$ TNF $\alpha, 1 \mu \mathrm{mol} / \mathrm{L}$ tolinapant, or a combination of TNF $\alpha /$ tolinapant for 24 hours. G, Tumor volume $\left(\mathrm{mm}^{3}\right)$ in HCT116, HT29, and DLD-1 xenograft models treated with vehicle and $16 \mathrm{mg} / \mathrm{kg}$ tolinapant. Data show mean tumor volume per treatment group per timepoint \pm SEM (HCT116; vehicle $n=10$, tolinapant $n=10$, HT29; vehicle $n=7$, tolinapant $n=7$, SW620; vehicle $n=10$, tolinapant $n=12$ ). Results were compared using a two-tailed Student $t$ test, ${ }^{*}, P<0.05$; ${ }^{* *}, P<0.01$; and ${ }^{* * *}, P<0.001$ 
apoptosis was observed in three of five models (HCT116, SW620, and HT29) cotreated and tolinapant/TNF $\alpha$ (Fig. 3A and B). Tolinapant alone also significantly enhanced FOLFOX-induced apoptosis in the HCT116 and SW620 models, albeit to a lesser extent than in the tolinapant/TNF $\alpha$ combination group (Fig. $3 \mathbf{A}$ and $\mathbf{B}$ ). In contrast, the DLD1 model was relatively resistant to the combination (Supplementary Fig. S3A), whereas interestingly, LoVo cells, which were relatively insensitive to the tolinapant/TNF $\alpha$ combination alone, exhibited significantly increased chemotherapy-induced apoptosis when cotreated with tolinapant alone as well as tolinapant/TNF $\alpha$ (Supplementary Fig. S3A and S3B). These results were reflected by qualitative assessment of apoptosis by PARP cleavage (Fig. 3B; Supplementary Fig. S3B).

We extended these studies to Apc-null, Kras-mutant(AK) murine colorectal cancer organoid models $(16,17)$. We also examined the impact of p53 status in these models given the high frequency of its mutation in advanced colorectal cancer. We observed striking combinatorial effects when both p53-proficient "AK" and p53-deficient "AKP" organoids were cotreated with FOLFOX and tolinapant/TNF $\alpha$ (Fig. 3C and D). cIAP1 expression was similar in the two organoid models, and tolinapant effectively targeted murine cIAP1 (Fig. 3E). Taking the AKP model into the in vivo setting in immune-competent syngeneic mice, we found that the combination treatment of FOLFOX/ tolinapant resulted in significant tumor regression compared with the individual treatments (Fig. 3F), and in vivo on-target activity of tolinapant was confirmed (Fig. 3G; Supplementary Fig. S3C).

\section{FLIP downregulation in response to FOLFOX sensitizes colorectal cancer cells to tolinapant}

We and others have previously demonstrated the importance of the caspase-8 paralog and regulator FLIP/CFLAR as a key mediator of resistance to IAP inhibitors in multiple cancers $(18,21)$. Notably, protein expression of the short FLIP splice form [FLIP(S)] and XIAP were significantly reduced following FOLFOX treatment in all five models; FLIP(L) was also downregulated in each model at one timepoint at least, although to a lesser extent than FLIP(S) (Fig. 3B; Supplementary Fig. S3B). FLIP(L) was also found to be reduced in response to FOLFOX in several tumors in the in vivo AKP experiment (Supplementary Fig. S3D). As tolinapant is active against XIAP (8), we hypothesized that the impact of FOLFOX on FLIP was more likely to be responsible for the enhanced effects of tolinapant in FOLFOXtreated colorectal cancer cells, particularly in the HCT116 and SW620 KRAS mutant models where FLIP downregulation and the extent of synergy were most marked. Moreover, high FLIP mRNA expression corresponded with resistance to tolinapant/TNF $\alpha$ in the extended cell line panel (Figs. 2A and 4A), further supporting the importance of FLIP in modulating response to tolinapant in colorectal cancer cells. Somewhat surprisingly, models with high caspase- 8 mRNA expression were also more resistant to tolinapant/TNF $\alpha$, although this can be explained, at least in part, by the close correlation between caspase- 8 and FLIP mRNA expression which are encoded on the same genomic locus (Fig. 4A). Consistent with a role for FLIP in mediating resistance to tolinapant/TNF $\alpha$, RNAi-mediated downregulation of FLIP significantly enhanced the induction of apoptosis by tolinapant/TNF $\alpha$ in all but the LoVo model as assessed in short-term cell death (Fig. 4B) and longer-term cell viability (Fig. 4C) assays; moreover, these results were confirmed qualitatively by Western blot analysis of PARP cleavage (Fig. 4D; Supplementary Fig. S3E).

Together, these results indicate that FLIP acts as a key mediator of resistance to tolinapant in colorectal cancer cells, consistent with downregulation of FLIP being a major contributor to the enhanced efficacy of tolinapant in FOLFOX-treated cells. To formally assess this, we made use of HCT116 cell line models stably expressing retroviral trans-genes encoding either FLIP(L), FLIP(S), or a FADD binding deficient mutant form of FLIP(S) (F114A) compromised in its ability to inhibit procaspase-8 homodimerization (Fig. 5A; ref. 26). Overexpression of FLIP(S), the more potent caspase-8 inhibitory form of FLIP (27), significantly abrogated apoptosis induced by FOLFOX in combination with tolinapant/TNF $\alpha$ (Fig. 5B), whereas expression of the FLIP(L) trans-gene failed to protect HCT116 cells from apoptosis induced by FOLFOX in combination with tolinapant/TNF $\alpha$ (likely due in part to the relatively small degree of FLIP(L) overexpression in this model; Fig. 5A). Overexpression of the F114A mutant of FLIP(S) failed to confer protection, indicating that it is FLIP(S)'s interaction with FADD that blocks caspase-8-dependent apoptosis in response to FOLFOX combination with tolinapant/TNF $\alpha$.

Compared with a HCT116 caspase-8 CRISPR knockout (KO) model in which cell death induced by the tolinapant/TNF $\alpha$-FOLFOX combination was almost completely abrogated (Fig. 5C and D), significant cell death was still observed in response to the combination in the FLIP(S) overexpressing model (Fig. 5B), suggesting that additional factors other than FLIP downregulation contribute to the effects of the combination. The role of caspase-8's other paralog caspase-10/ CASP10 as a regulator of apoptotic cell death is controversial, with both pro- and antiapoptotic roles described previously $(20,28,29)$. We found that cotreatment of HCT116 cells with tolinapant/TNF $\alpha / F O L-$ FOX dramatically reduced the levels of procaspase- 10 expression (Fig. 5C). Loss of the pro-form of procaspases can be indicative of activation and suggested participation of procaspase- 10 in the overall mechanism of apoptosis induction. However, in the absence of procaspase-8, relatively little decrease of procaspase- 10 was observed (Fig. 5C). In contrast to the protective effect of loss of procaspase-8, we found that rather than attenuating cell death, siRNA-mediated downregulation of procaspase-10 significantly enhanced PARP cleavage and executioner caspase activation in response to tolinapant/TNF $\alpha$ (Fig. 5E and F). To further investigate this, we generated CRISPR models with either procaspase-8, procaspase-10 or both knocked out (Fig. 5G). In agreement with the RNAi results, KO of procaspase-10 enhanced apoptosis induction in response to tolinapant/TNF $\alpha$ in the presence of caspase-8 (Fig. 5G). These results reveal a hitherto unreported role for procaspase-10 in inhibiting the apoptotic response to IAP antagonists. Furthermore, this is consistent with SW620 cells, which exhibit the lowest levels of procaspase-10 expression, being the most sensitive to tolinapant/TNF $\alpha$, while DLD-1 cells, with the highest levels of procaspase-10, are highly resistant (Fig. 2B and F). Indeed, siRNA-mediated depletion of procaspase-10 also enhanced the sensitivity of DLD-1 cells to tolinapant/TNF $\alpha$ (Fig. 5E).

Mechanistically, the effects of FOLFOX on FLIP expression were not due to suppression of transcription; mRNA expression of FLIP(S) was upregulated at 24 hours by approximately twofold and FLIP(L) was upregulated by approximately fivefold at 48 hours (Supplementary Fig. S4A). Inhibition of histone deacetylases (HDAC) has previously been reported by us and others to result in reduced expression of both splice forms of FLIP, at transcriptional and posttranslational levels and augment cell death induced by activators of extrinsic cell death $(19,20)$. It was therefore notable that FOLFOX treatment downregulated expression of the class I HDACs (HDAC-1, HDAC-2, and HDAC-3) as did tolinapant/TNF $\alpha$ (Fig. 5H). Moreover, downregulation of HDAC1 and HDAC3 by both FOLFOX and tolinapant/TNF $\alpha$ was attenuated in CASP8-null cells, indicating that these effects are caspase-8-dependent and therefore potentially consequences of caspase- 8 activation. In contrast, FOLFOX-mediated downregulation 

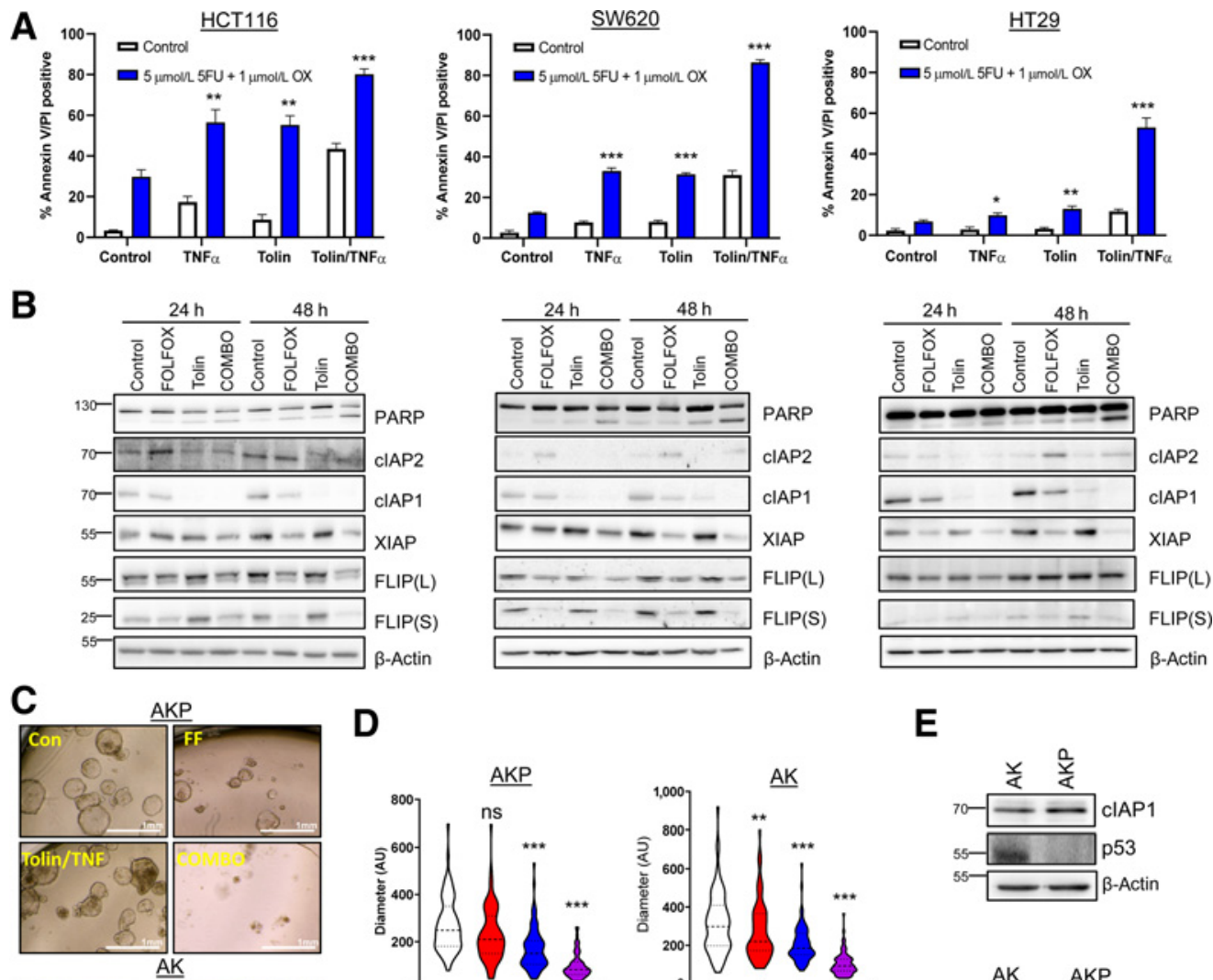

D

$\mathbf{E}$
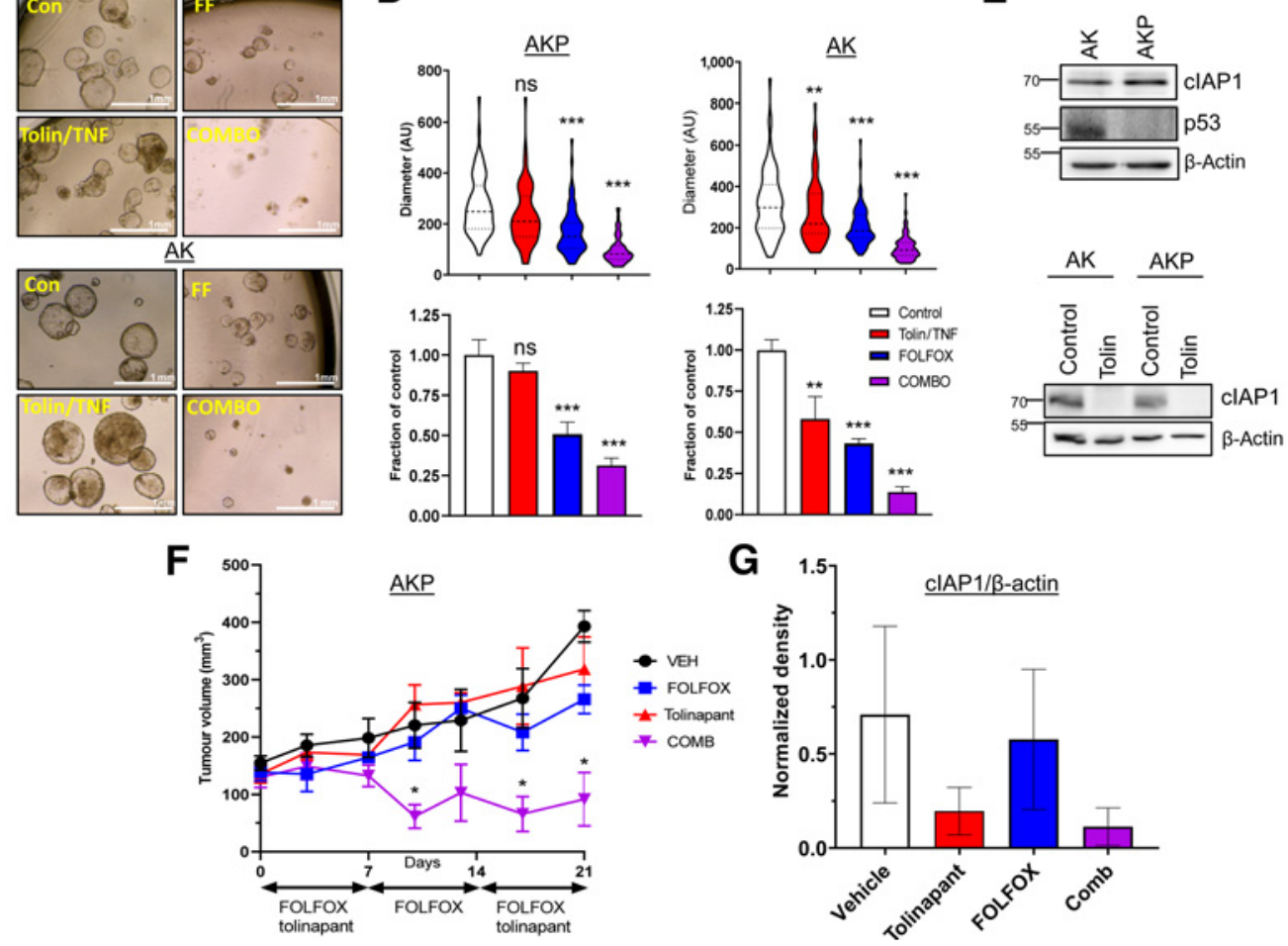

Figure 3.

Tolinapant synergizes with chemotherapy. A, Annexin V/PI analysis in HCT116, SW620, and HT29 cells treated with $1 \mathrm{ng} / \mathrm{mL}$ TNF $\alpha$, $1 \mu$ mol/L tolinapant, or a combination of tolinapant/TNF $\alpha$ in the presence and absence of $5 \mu \mathrm{mol} / \mathrm{L} 5 \mathrm{FU}$ and $1 \mu \mathrm{mol} / \mathrm{L}$ oxaliplatin (OX) for 72 hours. B, Western blot analysis of PARP, clAP2, CIAP1, XIAP, FLIP(L), FLIP(S), and $\beta$-actin in HCT116, SW620, and HT29 cells treated with $5 \mu \mathrm{mol} / \mathrm{L} 5 \mathrm{FU}$ and $1 \mu \mathrm{mol} / \mathrm{L}$ oxaliplatin (FOLFOX), $1 \mu \mathrm{mol} / \mathrm{L}$ tolinapant and a combination of FOLFOX/tolinapant (COMBO) for 24 and 48 hours. C, Pictures from AKP and AK organoids treated with $1 \mu \mathrm{mol} / \mathrm{L}$ tolinapant/1 ng/mL TNF $\alpha$ (tolin/ TNF), $5 \mu \mathrm{mol} / \mathrm{L} 5 \mathrm{FU}$ and $1 \mu \mathrm{mol} / \mathrm{L}$ oxaliplatin (FF) or combination (COMBO) for 72 hours. Diameter in AU from AKP ( $n=75$ for each treatment group) and AK ( $n=75$ for each treatment group) organoids treated with $1 \mu \mathrm{mol} / \mathrm{L}$ tolinapant/1 ng/mL TNF $\alpha$ (tolin/TNF), $5 \mu \mathrm{mol} / \mathrm{L} 5 \mathrm{FU}$ and $1 \mu \mathrm{mol} / \mathrm{L}$ oxaliplatin (FOLFOX) or combination (COMBO) for 72 hours. D, Cell viability assays in AKP and AK organoids treated with $1 \mu \mathrm{mol} / \mathrm{L}$ tolinapant/1 ng/mL TNF $\alpha$ (tolin/TNF), $5 \mu \mathrm{mol} / \mathrm{L} 5 \mathrm{FU}$ and $1 \mu \mathrm{mol} / \mathrm{L}$ oxaliplatin (FOLFOX) or combination (COMBO) for 72 hours. E, Western blot analysis of basal expression of clAP1, p53, and $\beta$-actin in AK and AKP organoids. Western blot analysis of CIAP1 and $\beta$-actin in AK and AKP organoids treated with $1 \mu \mathrm{mol} / \mathrm{L}$ tolinapant for 24 hours. F, Tumor volume (mm ${ }^{3}$ ) of AKP organoids transplanted into $\mathrm{C} 57 \mathrm{BL} / 6$ mice treated with vehicle $(n=3), 5 \mathrm{FU}(10 \mathrm{mg} / \mathrm{kg})+$ oxaliplatin ( $1 \mathrm{mg} / \mathrm{kg} ;$ FOLFOX; $n=4)$, tolinapant $(16 \mathrm{mg} / \mathrm{kg} ; n=4)$ and combination ( $n=4)$. Data show mean tumor volume per treatment group per timepoint \pm SEM. G, Densitometry from Western blot analysis of cIAP1 normalized to $\beta$-actin in AKP organoids transplanted into C57BL/6 mice and treated with vehicle $(n=3), 5 F U(10 \mathrm{mg} / \mathrm{kg})+$ oxaliplatin $(1 \mathrm{mg} / \mathrm{kg} ; \mathrm{FOLFOX} ; n=4)$, tolinapant (16 mg/kg; $n=4)$, and combination $(n=3)$. Results were compared using a two-tailed Student $t$ test, ${ }^{*}, P<0.05$; $^{* *}, P<0.01$; and ${ }^{* * *}, P<0.001$. 
A FLIP mRNA vs tolin/TNF response

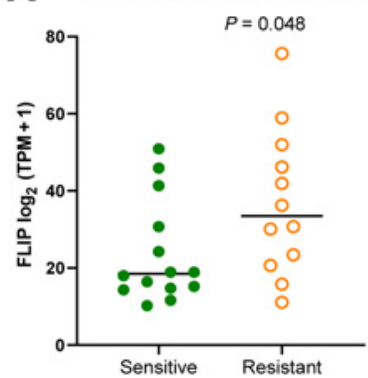

B
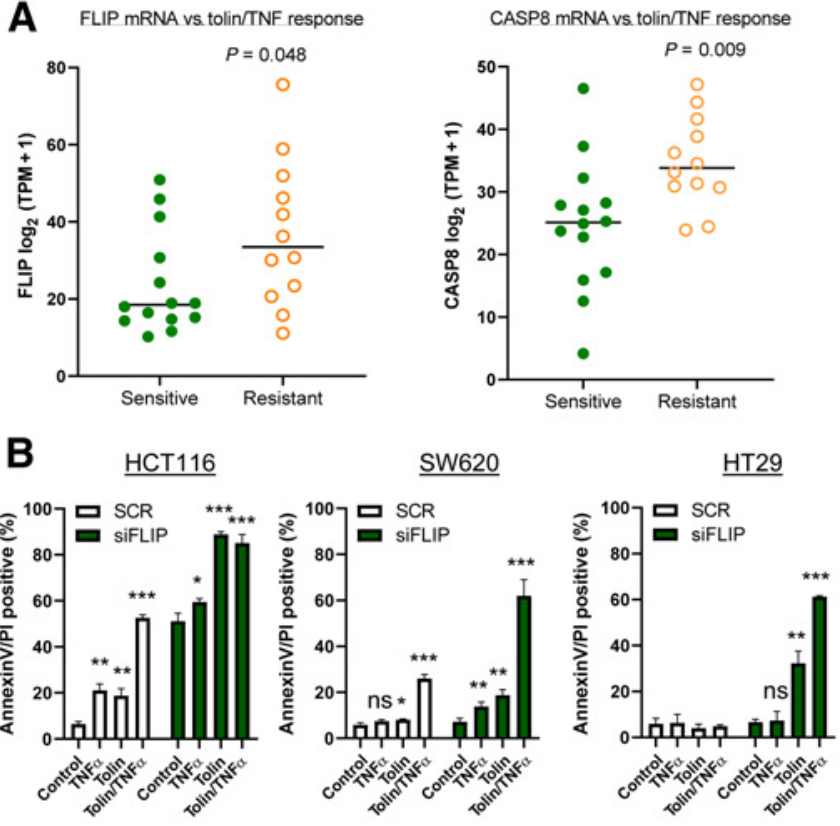

C
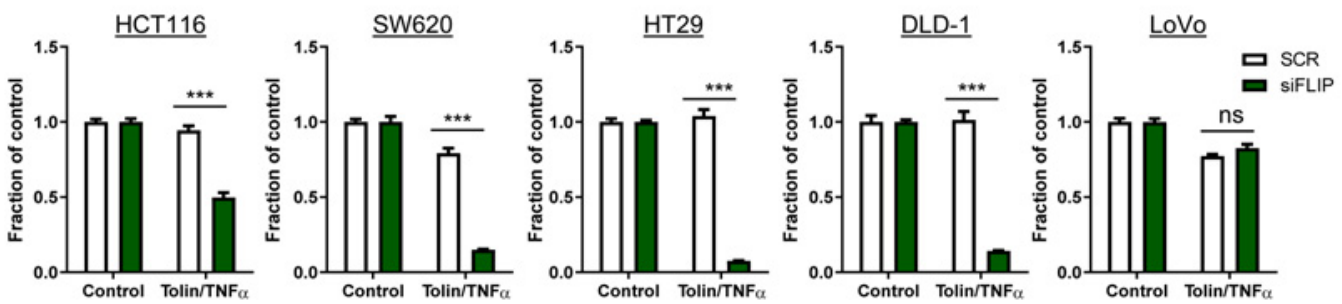

D

$\underline{\mathrm{HCT} 116}$

SW620
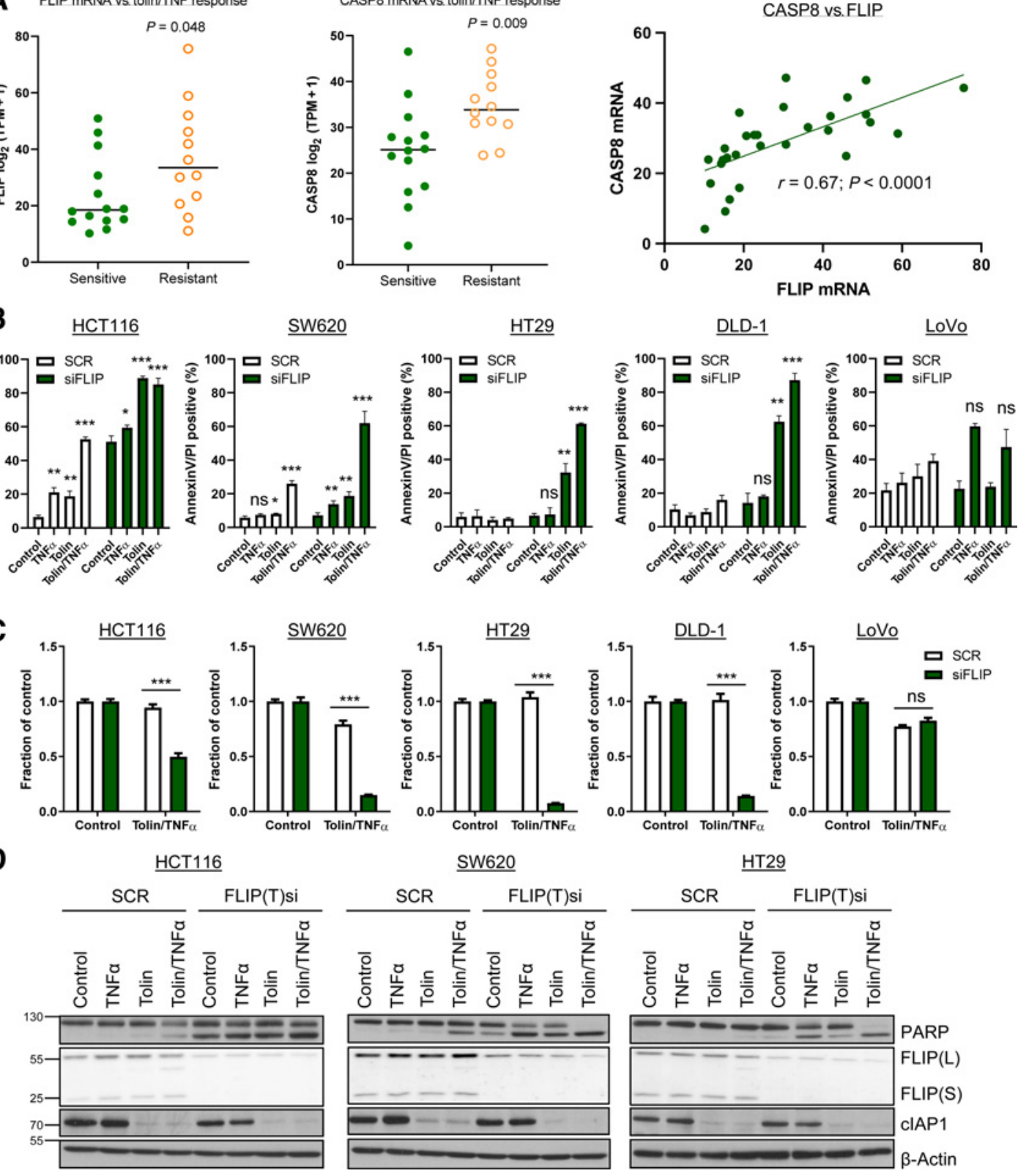

Figure 4.

Role of FLIP in determining sensitivity to tolinapant. A, Expression of caspase-8 and FLIP mRNA [ $\log _{2}$ (TPM (transcripts per million) +1] in colorectal cancer cell lines categorized as sensitive or resistant to tolinapant/TNF $\alpha$ in the cell line screen in Fig. 2A. B, Annexin V/PI analysis in HCT116, SW620, HT29, DLD-1, and LoVo cells transfected with control (SCR) and FLIP(T) siRNA for 24 hours prior to treatment with $1 \mu \mathrm{mol} / \mathrm{L}$ tolinapant and $1 \mathrm{ng} / \mathrm{mL}$ TNF $\alpha$ for a further 24 hours. C, Cell viability assays in HCT116, SW620, HT29, DLD-1, and LoVo cells transfected with control (SCR) and FLIP(T) siRNA for 6 hours prior to treatment with $1 \mu \mathrm{mol} / \mathrm{L}$ tolinapant and $1 \mathrm{ng} / \mathrm{mL}$ TNF $\alpha$ for a further 24 hours. D, Western blot analysis of PARP, FLIP(L), FLIP(S), CIAP1, and $\beta$-actin and in HCT116, SW620, and HT29 cells transfected with control (SCR) and FLIP(T) siRNA for 24 hours prior to treatment with $1 \mu \mathrm{mol} / \mathrm{L}$ tolinapant and $1 \mathrm{ng} / \mathrm{mL}$ TNF $\alpha$ for a further 24 hours. Results were compared using a two-tailed Student $t$ test, ${ }^{*}, P<0.05 ;{ }^{* *}, P<0.01$; and ${ }^{* * *}, P<0.001$.

of HDAC2 was caspase-8-independent, suggesting that this is an event upstream of caspase- 8 activation. We previously found that HDAC inhibitors modulate FLIP expression at the posttranscriptional level by inducing acetylation of Ku70, a central component of the nonhomologous end-joining (NHEJ) DNA damage repair pathway (19). In its nonacetylated form, Ku70 binds FLIP and inhibits its proteasomal degradation; however, its acetylation in response to HDAC inhibitors blocks this interaction, leading to FLIP degradation. It was therefore notable that FOLFOX caused significant Ku70 acetylation (Fig. 5I). Moreover, silencing Ku70 not only resulted in decreased levels of FLIP, it also enhanced apoptosis induced by tolinapant/TNF $\alpha$ as assessed by PARP cleavage and executioner caspase activation (Fig. 5J). In further support of this mechanism, we also found that entinostat, a class I-selective HDAC inhibitor potently induced 

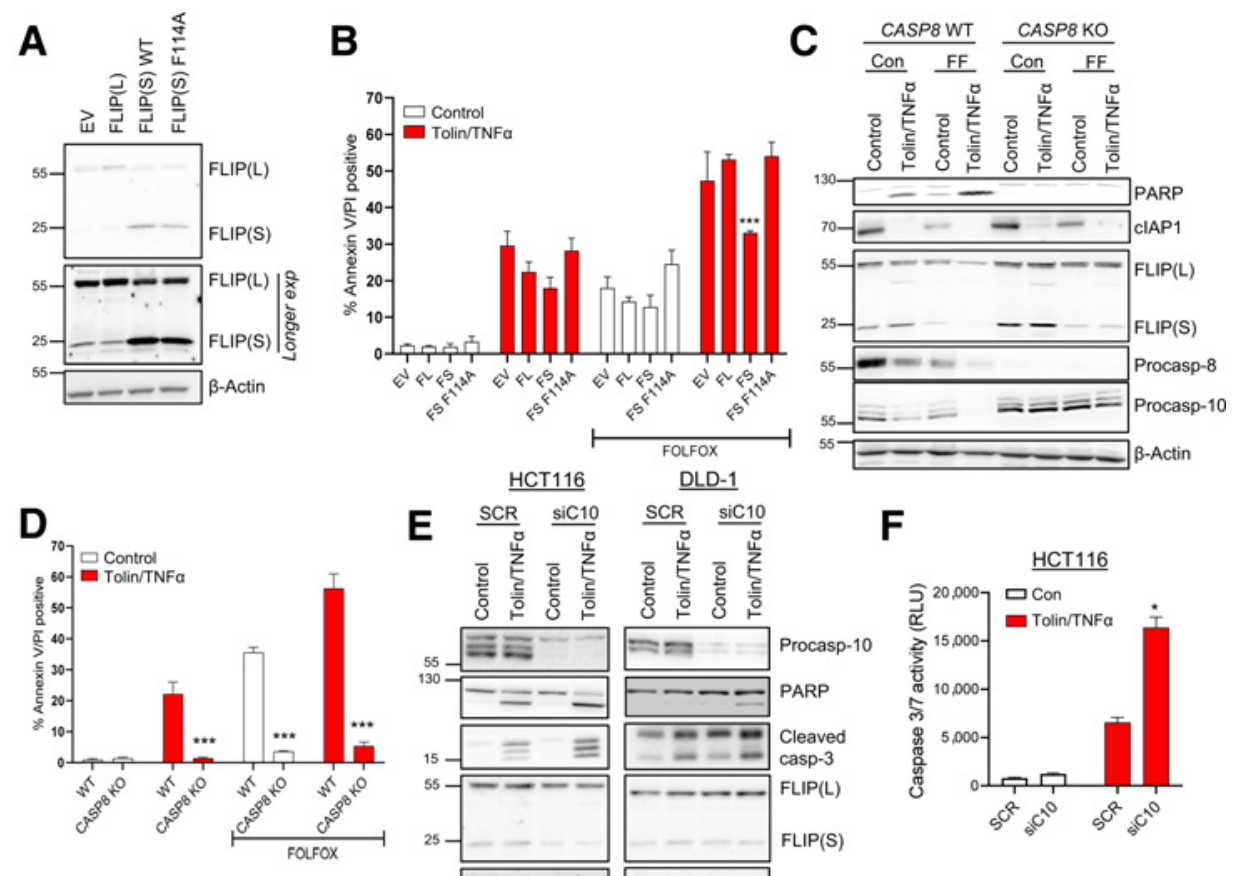

$\underline{\text { DLD-1 }}$
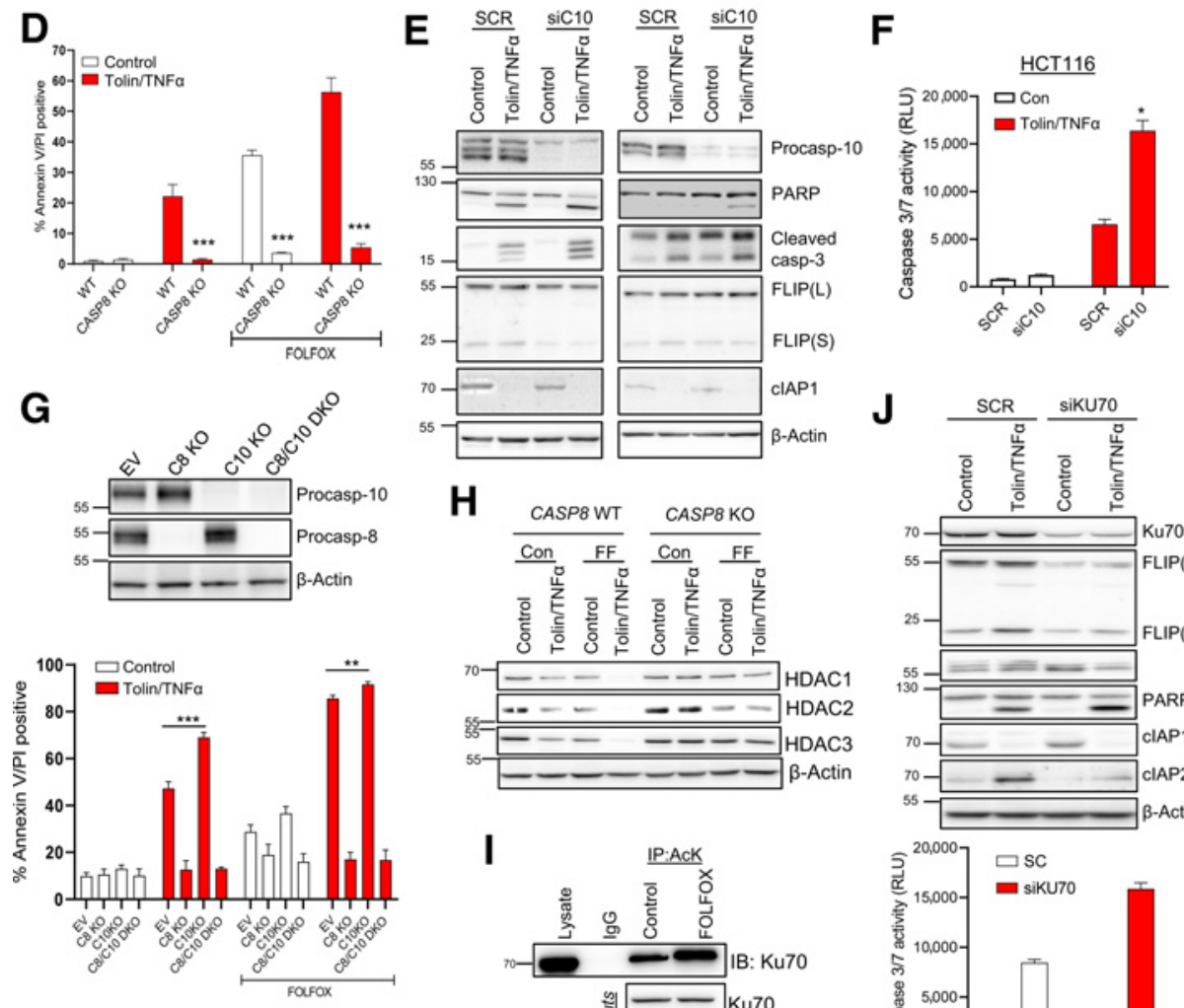

H
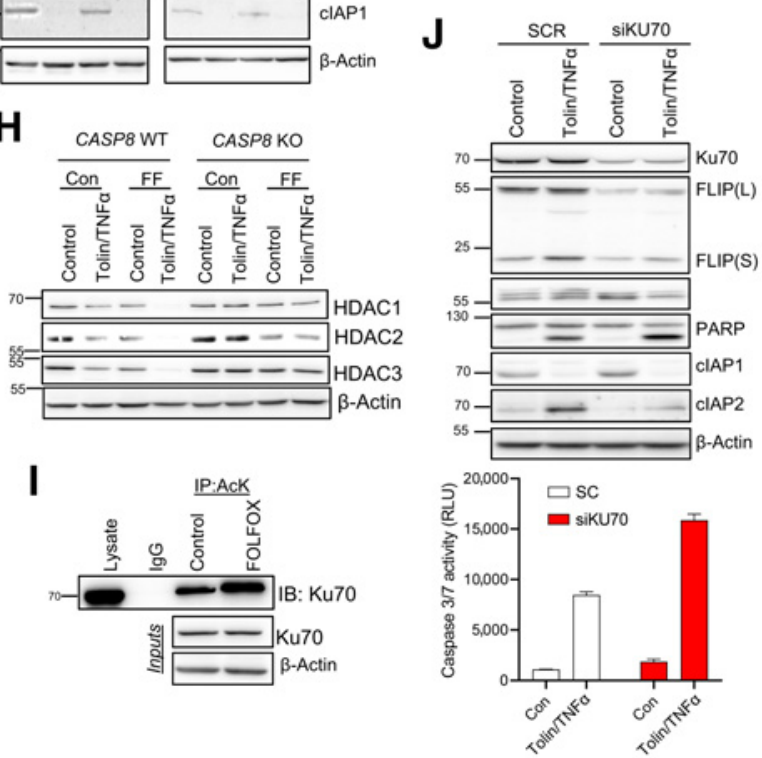

Figure 5.

Mechanism of chemotherapy-induced sensitization to tolinapant. A, Western blot analysis of FLIP(L), FLIP(S), and $\beta$-actin in HCT116 cells retrovirally overexpressing pbabe empty vector (EV), pbabe FLIP(S), pbabe FLIP(S) F114A, and pbabe FLIP(L). B, Annexin V/PI analysis of in HCT116 cells retrovirally overexpressing pbabe empty vector (EV), pbabe FLIP(S), pbabe FLIP(S) F114A, and pbabe FLIP(L) following treatment with $1 \mu \mathrm{mol} / \mathrm{L}$ tolinapant $/ 1 \mathrm{ng} / \mathrm{mL} \mathrm{TNF} \alpha, 5 \mu \mathrm{mol} / \mathrm{L} 5 \mathrm{FU}$, and $1 \mu \mathrm{mol} / \mathrm{L}$ oxaliplatin (FOLFOX) or combination for 48 hours. C, Western blot analysis of PARP, CIAP1, FLIP(L), FLIP(S), procaspase-8, procaspase-10, and $\beta$-actin in HCT116 WT and HCT116 caspase-8 $\mathrm{KO}$ cells treated with $1 \mu \mathrm{mol} / \mathrm{L}$ tolinapant $/ 1 \mathrm{ng} / \mathrm{mL}$ TNF $\alpha$ (tolin/TNF $\alpha$ ), $5 \mu \mathrm{mol} / \mathrm{L} 5 \mathrm{FU}$ and $1 \mu \mathrm{mol} / \mathrm{L}$ oxaliplatin (FF) or combination for $48 \mathrm{hours}$. D, Annexin V/PI analysis in HCT116 WT and HCT116 caspase-8 KO cells treated with $1 \mu \mathrm{mol} / \mathrm{L}$ tolinapant $/ 1 \mathrm{ng} / \mathrm{mL} \mathrm{TNF} \alpha, 5 \mu \mathrm{mol} / \mathrm{L} 5 \mathrm{FU}$, and $1 \mu \mathrm{mol} / \mathrm{L}$ oxaliplatin (FOLFOX) or combination for 72 hours. E, Western blot analysis of procaspase-10, PARP, cleaved caspase-3, FLIP(L), FLIP(S), cIAP1, and $\beta$-actin in HCT116 and DLD1 cells transfected with control (SCR) and caspase-10 (siC10) siRNA for 24 hours prior to treatment with $1 \mu \mathrm{mol} / \mathrm{L}$ tolinapant and $1 \mathrm{ng} / \mathrm{mL} \mathrm{TNF} \alpha$ for a further $24 \mathrm{hours}$. F, Caspase-3/7 activity assay in HCT116 cells transfected with control (SCR) and caspase-10 siRNA (siC10) for 24 hours prior to treatment with $1 \mu \mathrm{mol} / \mathrm{L}$ tolinapant and $1 \mathrm{ng} / \mathrm{mL}$ TNF $\alpha$ (tolin/TNF $\alpha$ ) for a further 24 hours. G, Western blot analysis of procaspase-10, procaspase-8, and $\beta$-actin in HCT116 WT, HCT116 caspase-8 KO, HCT116 caspase-10 KO and HCT116 caspase-8/caspase-10 DKO cells, and Annexin V/PI analysis in HCT116 WT and HCT116 caspase-8 KO, HCT116 caspase-10 KO and HCT116 caspase-8/caspase-10 DKO cells treated with $1 \mu \mathrm{mol} / \mathrm{L}$ tolinapant $/ 1 \mathrm{ng} / \mathrm{mL}$ TNF $\alpha, 5 \mu \mathrm{mol} / \mathrm{L} 5 \mathrm{FU}$ and $1 \mu \mathrm{mol} / \mathrm{L}$ oxaliplatin (FOLFOX) or combination for 48 hours. H, Western blot analysis of HDAC1, HDAC2, HDAC3, and $\beta$-actin in HCT116 WT and HCT116 caspase-8 KO cells treated with $1 \mu \mathrm{mol} / \mathrm{L}$ tolinapant/1 ng/mL TNF $\alpha$ (tolin/ TNFo), $5 \mu \mathrm{mol} / \mathrm{L} 5 \mathrm{FU}$, and $1 \mu \mathrm{mol} / \mathrm{L}$ oxaliplatin (FF) or combination for 48 hours. I, Western blot analysis of Ku70 following immunoprecipitation of acetylated lysine (ACK) from HCT116 cells treated with $5 \mu \mathrm{mol} / \mathrm{L} 5 \mathrm{FU}$ and $1 \mu \mathrm{mol} / \mathrm{L}$ oxaliplatin (FOLFOX) for 24 hours. An IgG isotype control was used as a control. J, Western blot and caspase-3/7 activity analyses of Ku70, FLIP(L), FLIP(S), procaspase-10, PARP, CIAP1, CIAP2, XIAP, and $\beta$-actin and in HCT116 cells transfected with control (SCR) and Ku70 siRNA (siKU70) for 24 hours prior to treatment with $1 \mu \mathrm{mol} / \mathrm{L}$ tolinapant and $1 \mathrm{ng} / \mathrm{mL}$ TNF $\alpha$ (tolin/TNF $\alpha$ ) for a further 24 hours. 
acetylation of Ku70 (Supplementary Fig. S4B) downregulated FLIP(L) and FLIP(S) (Supplementary Fig. S4C) and sensitized all but the LoVo cells to tolinapant/TNF $\alpha$ (Supplementary Fig. S4D); this is consistent with the latter's lack of sensitization by FLIP silencing (Fig. 4B; Supplementary Fig. S3E). Moreover, HCT116 and DLD-1 cells caspase- $8 \mathrm{KO}$ cells were resistant to cell death induced by the entinostat/ tolinapant/TNF $\alpha$ (Supplementary Fig. S4E) as was an HCT116 FADD-deficient model (Supplementary Fig. S4F). In addition, overexpression of either FLIP(L) or FLIP(S) abrogated the sensitization of HCT116 cells to tolinapant/TNF $\alpha$ by entinostat (Supplementary Fig. S4G), indicating that entinostat-mediated sensitization is more FLIP dependent than FOLFOX-mediated sensitization, which was only inhibited by the more highly overexpressed and more potent caspase-8 inhibitor FLIP(S) (Fig. 5B).

\section{Loss or inhibition of caspase-8 leads to necroptosis induction in response to tolinapant/TNF $\alpha$ in RIPK3 positive colorectal cancer models}

Entinostat was also shown to sensitize HT29 wild-type (WT) cells to tolinapant/TNF $\alpha$ (Fig. 6A); however, unlike the rescue that was observed in HCT116 and DLD-1 cells (Supplementary Fig. S4E), CRISPR KO of caspase- 8 in HT29 cells resulted in enhanced sensitivity to tolinapant/TNF $\alpha$ (and tolinapant alone), even in the absence of entinostat (Fig. 6A). This effect was abrogated by the necroptosis inhibitor, necrosulfonamide, but not by the pan-caspase inhibitor zVAD, indicating that it is due to the induction of necroptosis rather than apoptosis (Supplementary Fig. S5A). Necroptosis is a proinflammatory, RIPK1/RIPK3dependent, but caspase-independent form of programmed cell death. Of the human colorectal cancer cell lines profiled for tolinapant activity, only HT29 and SW620 cells expressed RIPK3 at the protein (Fig. 2B) and mRNA levels (Supplementary Fig. S5B). Necroptosis induction was also observed in SW620 CASP8 KO cells (Supplementary Fig. S5C). These results were further supported by Western blot analyses, which demonstrated phosphorylation of RIPK1, RIPK3 and the effector of necroptosis, MLKL (mixed lineage kinase domain-like) in caspase-8-deficient HT29 (Fig. 6B) and SW620 cells (Supplementary Fig. S5D). Moreover, direct assessment of cell death (propidium iodide positivity) further confirmed that the mechanism of cell death induced by tolinapant/TNF $\alpha$ in caspase-8-deficient HT29 (Fig. 6C) and SW620 cells (Supplementary Fig. S5E) was via necroptosis. Furthermore, FADD-deficient HT29 cells were also sensitive to tolinapant/TNF $\alpha$, a cell death phenotype that was not rescued through inhibition of caspases (Supplementary Fig. S5F).

Notably, the pan-caspase inhibitor zVAD induced necroptotic cell death in response to tolinapant/TNF $\alpha$ in parental HT29 cells (Fig. 6C; Supplementary Fig. S6A), but was less efficient at doing so in SW620 cells (Supplementary Fig. S5C and S5E). zVAD also sensitized AK and AKP mouse organoids to tolinapant/TNF $\alpha$ (Supplementary Fig. S6B). We therefore investigated the potential of caspase inhibition as a combination partner for tolinapant in RIPK3-positive colorectal cancer using emricasan (IDN-6556), a pan-caspase inhibitor already under evaluation in clinical trials in chronic liver disease (30). Pretreatment of HT29 or SW620 cells with emricasan resulted in marked sensitization to necroptosis induced by tolinapant/TNF $\alpha$ (Fig. 6D and E; Supplementary Fig. S6C-S6E) and was considerably more efficacious than $\mathrm{zVAD}$. These findings were mirrored in the AK and AKP mouse organoid models, where significant combinatorial effects and necroptotic pathway activation were also observed (Fig. 6F and G; Supplementary Fig. S6F).

\section{Discussion}

Colorectal cancer is the second leading cause of cancer deaths in the Western world, with resistance to programmed cell death contributing to treatment failure. Multiple IAPs are overexpressed in colorectal cancer and correlate with therapy resistance and poorer survival rates, making them an attractive target for cancer therapy $(31,32)$. Here, we report that stage III chemotherapy-treated patients with MSS colorectal tumors with elevated expression of cIAP1 or cIAP2 (but not XIAP) have a poor prognosis. This finding makes cIAP1/2-high MSS colorectal cancer a particularly attractive subpopulation for IAPtargeted therapeutics.

Preclinically, IAP antagonists, including tolinapant, synergize with multiple anticancer therapies, including radiotherapy, chemotherapy, TRAIL receptor agonists, and hypomethylating agents as well as showing promise in combination with PD-1/PD-L1 blockade $(33,34)$. Overall, despite demonstrating potent on-target activity through rapid and sustained downregulation of cIAP1, colorectal cancer cell lines showed a limited response to tolinapant alone, although sensitivity was significantly enhanced in many cell lines in the context of cotreatment with TNFo. This cotreatment reflects the significant enrichment for TNF $\alpha$ signaling in cIAP1/2-high tumors (Fig. 1C) presumably due to elevated levels of immune cells (Fig. 1D) despite these being MSS tumors that are reported to be predominantly immune cold (35). cIAP1/2 are both canonical target genes of NFKB (36), suggesting that elevation of TNF $\alpha$ signaling may be the driver for enhanced IAP expression in these poor prognostic tumors. Moreover, we found that tolinapant/TNF $\alpha$ enhanced cell death induced by FOLFOX, the SoC regimen for colorectal cancer, in several human and mouse colorectal cancer models in vitro, with preclinical antitumor activity also demonstrated in vivo, where it was well tolerated, suggesting its potential in combination with SoC chemotherapy.

Mechanistically, FOLFOX downregulated expression of FLIP, a pseudoenzyme paralog of caspase-8 leading to enhanced caspase-8dependent cell death in response to tolinapant. FLIP negatively regulates apoptosis induction from complex II by inhibiting procaspase- 8 homodimerization, a prerequisite for the latter's activation to its apoptosis-inducing catalytic form (37). The caspase-8/FLIP(L) heterodimer [but not the caspase-8/FLIP(S) heterodimer] also has catalytic activity, which can inhibit necroptotic signaling from complex IIa/b through the cleavage and inactivation of RIPK1/3 (38). We and others have previously identified FLIP as a mediator of resistance to IAP antagonist therapy in multiple cancers, including mesothelioma and castrate-resistant prostate cancer $(18,21)$. Class I HDACs (HDAC1/2/3) have been found to be overexpressed in colorectal cancer and promote resistance to chemotherapy (39). Here, we found that FOLFOX treatment resulted in downregulation of the class I HDACs and acetylation of their substrate Ku70, an essential component of the NHEJ DNA damage repair machinery that repairs double-strand breaks, including those induced by DNA-damaging chemotherapy, such as FOLFOX (40). We have previously reported that Ku70 binds to and enhances FLIP stability when in its nonacetylated form (19), a finding corroborated by others. Consistent with this, silencing Ku70 resulted in FLIP downregulation and enhancement of tolinapant/ TNF $\alpha$-induced cell death. Moreover, the oral class I HDAC inhibitor, entinostat, which is well tolerated in humans, also acetylated Ku70 and downregulated FLIP expression resulting in sensitization to tolinapant in the majority of colorectal cancer models.

Procaspase-10 shares significant homology with procaspase-8: they are $46 \%$ identical in their catalytic domains, and overexpression of procaspase- 10 splice forms $10 \mathrm{~A}$ and $10 \mathrm{D}$ has been shown to resensitize 
A

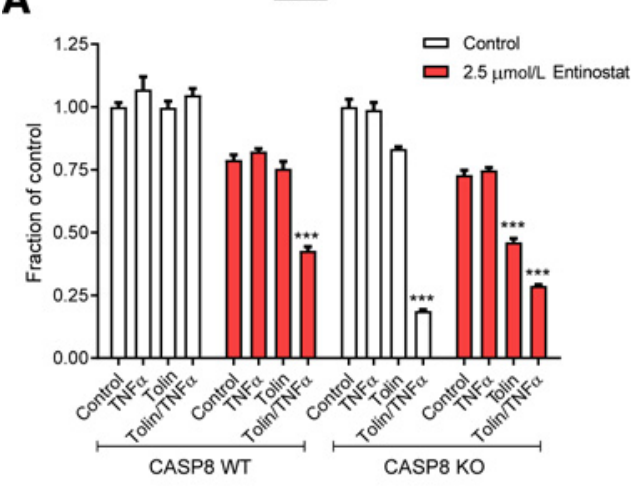

B

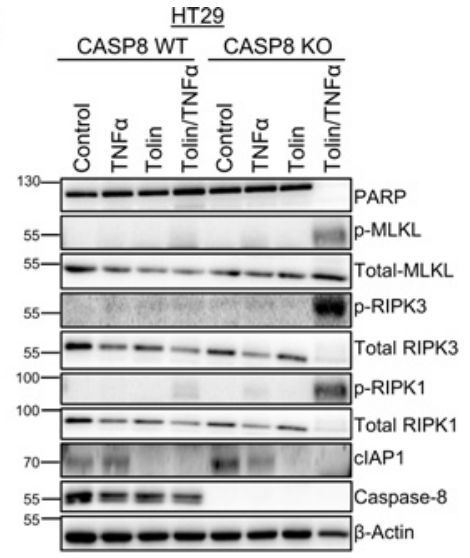

C
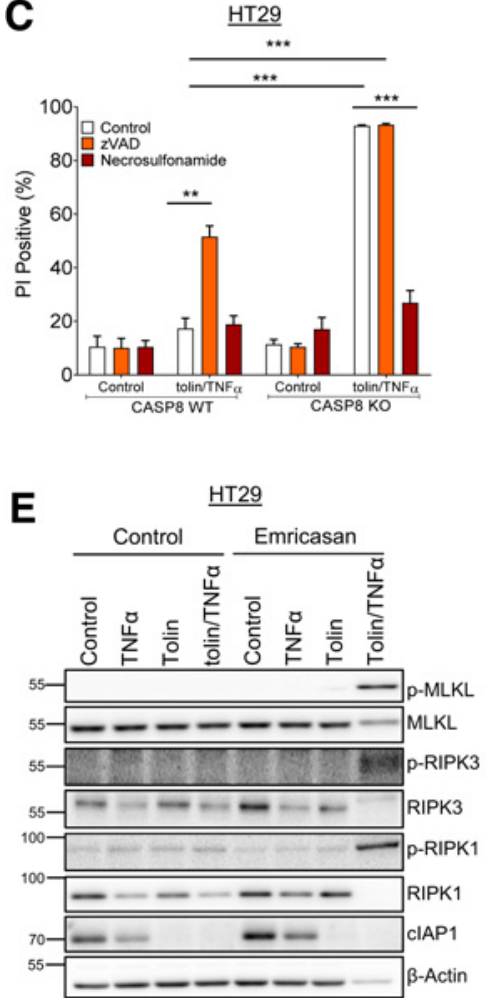

D

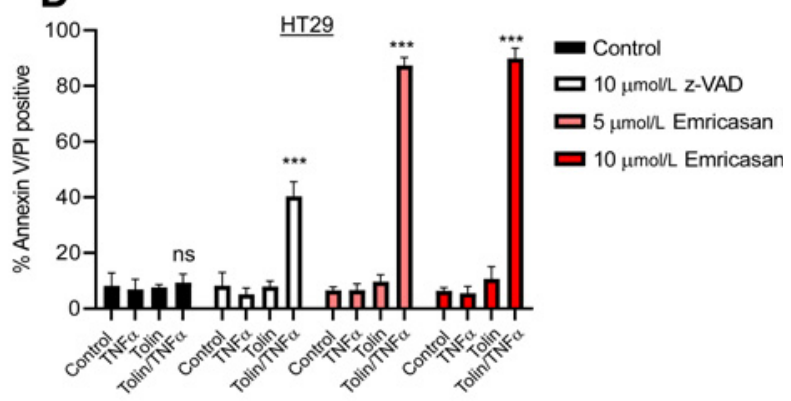

$\mathbf{F}$

G
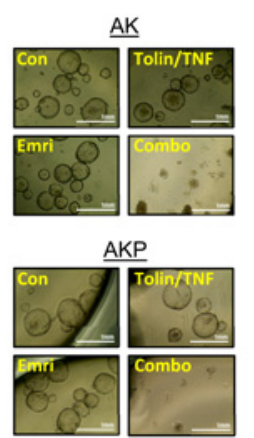

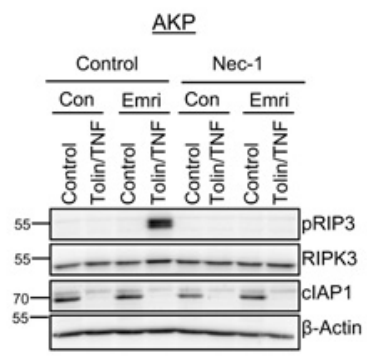

\section{Figure 6.}

Necroptotic cell death induced by tolinapant in RIPK3-expressing colorectal cancer cells. A, Cell viability assays in HT29 caspase-8 WT and HT29 caspase-8 KO cells pretreated with $2.5 \mu \mathrm{mol} / \mathrm{L}$ entinostat for 24 hours then addition of $1 \mu \mathrm{mol} / \mathrm{L}$ tolinapant and $1 \mathrm{ng} / \mathrm{mL}$ TNF $\alpha$ for a further 24 hours. B, Western blot analysis of PARP, p-MLKL(Ser358), total MLKL, p-RIPK3(Ser227), total RIPK3, p-RIPK1(Ser166), total RIPK1, cIAP1, caspase-8, and $\beta$-actin in HT29 caspase-8 WT and HT29 caspase-8 KO cells 24 hours following treatment with $1 \mu \mathrm{mol} / \mathrm{L}$ tolinapant and $1 \mathrm{ng} / \mathrm{mL}$ TNF $\alpha$. C, PI analysis in HT29 caspase-8 WT and HT29 caspase-8 KO cells pretreated for 30 minutes with $10 \mu \mathrm{mol} / \mathrm{L} z-V A D$ and $2 \mu \mathrm{mol} / \mathrm{L}$ necrosulfonamide then addition of $1 \mu \mathrm{mol} / \mathrm{L}$ tolinapant and $1 \mathrm{ng} / \mathrm{mL}$ TNF $\alpha$ for 24 hours. D, Annexin V/PI analysis in HT29 cells pretreated with $10 \mu \mathrm{mol} / \mathrm{L} \mathrm{z-VAD,} 5 \mu \mathrm{mol} / \mathrm{L}$ emricasan or $10 \mu \mathrm{mol} / \mathrm{L}$ emricasan for 30 minutes then addition of $1 \mu \mathrm{mol} / \mathrm{L}$ tolinapant and $1 \mathrm{ng} / \mathrm{mL} \mathrm{TNF} \alpha$ for 24 hours. E, Western blot analysis of p-MLKL(Ser358), total MLKL, p-RIPK3(Ser227), total RIPK3, p-RIPK1 (Ser166), total RIPK1, cIAP1, and $\beta$-actin in HT29 cells pretreated with $10 \mu \mathrm{mol} / \mathrm{L}$ emricasan for 30 minutes then addition of $1 \mu \mathrm{mol} / \mathrm{L}$ tolinapant and $1 \mathrm{ng} / \mathrm{mL}$ TNF $\alpha$ for 24 hours. F, Pictures from AK and AKP organoids pretreated with $10 \mu \mathrm{mol} / \mathrm{L}$ emricasan for 30 minutes then addition of $1 \mu \mathrm{mol} / \mathrm{L}$ tolinapant and $1 \mathrm{ng} / \mathrm{mL}$ TNF $\alpha$ for 48 hours. G, Western blot analysis of $p$-RIPK3 (Thr231/ Ser232), total RIPK3, CIAP1, and $\beta$-actin in AKP organoids pretreated with $10 \mu \mathrm{mol} / \mathrm{L}$ necrostatin-1 and $10 \mu \mathrm{mol} / \mathrm{L}$ emricasan (Emri) for 30 minutes before the addition of $1 \mu \mathrm{mol} / \mathrm{L}$ tolinapant and $1 \mathrm{ng} / \mathrm{mL}$ TNF $\alpha$ (tolin/TNF) for 24 hours. Results were compared using a two-tailed Student $t$ test, ${ }^{*}, P<0.05 ;{ }^{* *}, P<0.01 ;$ and ${ }^{* * *}, P<0.001$.

caspase-8-deficient cells to TRAIL (28). However, caspase-10 has also been shown to inhibit caspase- 8 activation by the Fas/CD95 death receptor, supporting earlier studies in which it was shown that the caspase-8/-10 heterodimer is inactive $(29,41)$. Our mechanistic studies are consistent with an inhibitory role for procaspase-10 in regulating apoptosis signaling from the death complexes induced by tolinapant/ TNF $\alpha$. To our knowledge, this is the first study to identify caspase- 10 as an inhibitor of complex IIa/b.

Necroptosis induced by TNF $\alpha$ signaling is a caspase-independent form of programmed cell death, dependent on RIPK1, RIPK3, and 
MLKL $(42,43)$. Necroptosis, unlike apoptosis, results in the activation of inflammatory responses through the release of damage-associated molecular patterns from dying cells, which promote antitumor immunity through recruitment of inflammatory cells, maturation of dendritic cells, and elicit cross-priming of $\mathrm{CD}^{+} \mathrm{T}$ cells $(44,45)$. RIPK3 expression is lost in multiple cancers, including many colorectal cancers, and correlates with cancer progression $(46,47)$. Loss of RIPK3 expression and necroptosis resistance is correlated with $B R A F$ gain-offunction mutations, AXL overexpression, and RIPK3 promoter hypermethylation (48). CRISPR-mediated KO of caspase-8 or FADD in RIPK3-positive colorectal cancer models resulted in dramatic induction of necroptosis by tolinapant/TNF $\alpha$. Thus, if clinical resistance to FOLFOX/tolinapant combination therapy emerges due to procaspase8 or FADD mutations, BRAF inhibitors, AXL inhibitors or epigenetic modifying agents that upregulate RIPK3 expression may make these resistant tumor cells sensitive to tolinapant-induced necroptosis.

Emricasan is an orally active caspase inhibitor that is well tolerated in humans. We found that tolinapant and emrciasan cotreatment potently activated necroptosis in the presence of TNF $\alpha$, but only in RIPK3-positive colorectal cancer models. Compared with zVAD, emricasan is a more potent inhibitor of the enzymatic activity of the caspase-8/FLIP(L) heterodimer that cleaves RIPK1 (49). Our data therefore suggest that tolinapant/emricasan combinations may be effective in proinflammatory, RIPK3-positive colorectal cancers.

Multiple IAP antagonists, including tolinapant, are currently in clinical trials, and single-agent clinical response was observed predominantly in lymphoma for tolinapant while responses in solid tumors were more limited (9). Tolinapant was recently granted orphan drug designation for the treatment of patients with T-cell lymphomas. Here, we have highlighted the potential of combining tolinapant with FOLFOX in colorectal cancer. This SoC chemotherapy is the mainstay of treatment in MSS colorectal cancer in the neoadjuvant, adjuvant, and advanced disease settings, hence strategies to overcome treatment resistance are required. There is a particular rationale for considering an oxaliplatin-based SoC combination, as preclinical modeling in other cancer types has demonstrated induction of expression of immunogenic cell death markers and enhanced response to radiation both in vivo (50) and clinically (7) in head and neck cancer. The potential mechanisms by which IAP antagonists may induce antitumor immune effects and hence antitumor activity beyond overcoming tumor cell resistance to apoptosis are under evaluation. While checkpoint inhibitors may seem a rational potential combination partner for IAP antagonists, at present, SoC chemotherapy remains a more attractive treatment option given the failure to date of checkpoint inhibitors alone or in combination with other agents in the immunecold tumor microenvironment of MSS colorectal cancer. This combination could be particularly beneficial in the treatment of stage III, cIAP1/2-high MSS disease, which, as we have reported here, has a particularly poor prognosis when treated adjuvantly with FOLFOX alone. We have also identified FLIP as an intrinsic resistance mech-

\section{References}

1. Van Schaeybroeck S, Allen WL, Turkington RC, Johnston PG. Implementing prognostic and predictive biomarkers in CRC clinical trials. Nat Rev Clin Oncol 2011;8:222-32.

2. Quasar Collaborative G, Gray R, Barnwell J, McConkey C, Hills RK, Williams NS, et al. Adjuvant chemotherapy versus observation in patients with colorectal cancer: a randomised study. Lancet 2007;370:2020-9.

3. Efficacy of adjuvant fluorouracil and folinic acid in colon cancer. International Multicentre Pooled Analysis of Colon Cancer Trials (IMPACT) investigators. Lancet 1995;345:939-44. anism to IAP antagonist therapy in colorectal cancer, the inhibitory effects of which can be overcome (at least in a subset of disease models) by FOLFOX treatment and the clinically relevant class I HDAC inhibitor, entinostat. Moreover, in RIPK3-positive colorectal cancer, the clinically well-tolerated caspase inhibitor, emricasan induces necroptotic cell death. Of note, this may be the preferred mode of cell death in the predominantly immune-cold MSS disease setting due to potent pro-inflammatory effects of necroptosis.

\section{Authors' Disclosures}

J.M. Munck reports personal fees from Astex Pharmaceuticals outside the submitted work. M. Lawler reports grants from Pfizer; personal fees from EMD Serono, Roche, BMS, and Carnall Farrar outside the submitted work. V.M. Coyle reports nonfinancial support from Astex Pharmaceuticals during the conduct of the study; personal fees from Servier and other support from Servier outside the submitted work. D.B. Longley reports grants from Astex Pharmaceuticals during the conduct of the study. No disclosures were reported by the other authors.

\section{Authors' Contributions}

N. Crawford: Conceptualization, resources, data curation, formal analysis, supervision, funding acquisition, investigation, methodology, writing-original draft, project administration, writing-review and editing. K.J. Stott: Conceptualization, data curation, formal analysis, supervision, investigation, methodology, writingoriginal draft, writing-review and editing. T. Sessler: Data curation, formal analysis, investigation. C. McCann: Investigation. W. McDaid: Investigation. A. Lees: Investigation. C. Latimer: Investigation. J.P. Fox: Investigation. J.M. Munck: Investigation. T. Smyth: Investigation. A. Shah: Investigation. V. Martins: Investigation. M. Lawler: Funding acquisition, writing-review and editing. P.D. Dunne: Funding acquisition, writing-review and editing. E.M. Kerr: Investigation, writing-review and editing. S.S. McDade: Conceptualization, formal analysis, supervision, funding acquisition, writing-original draft, writing-review and editing. V.M. Coyle: Conceptualization, funding acquisition, writing-original draft, writing-review and editing. D.B. Longley: Conceptualization, resources, data curation, formal analysis, supervision, funding acquisition, investigation, writing-original draft, project administration, writing-review and editing.

\section{Acknowledgments}

This work was supported by a studentship (K.J. Stott) sponsored by The Northern Ireland Department for the Economy (NI DfE), and by funding from a CRUK Program grant (D.B. Longley/S.S. McDade) C11884/A24367, a CRUK Experimental Cancer Medicine Centre (ECMC) program grant, (V.M. Coyle/D.B. Longley) C36697/A25176, a Northern Ireland Health and Social Care Research and Development award (V.M. Coyle/D.B. Longley/C. Latimer) COM/5535/19, a CRUK Career Development Fellowship (E.M. Kerr/W. McDaid) C61288/A26045. Additional support (D.B. Longley, C. McCann) was obtained from NI DfE (SFI-DEL 14/1A/2582 and STL/5715/15 - US-Ireland Partnership). T. Sessler and M. Lawler were supported by an HDR-UK grant (JHR1157-100/1230). D.B. Longley was also in receipt of direct funding from Astex Pharmaceuticals.

The costs of publication of this article were defrayed in part by the payment of page charges. This article must therefore be hereby marked advertisement in accordance with 18 U.S.C. Section 1734 solely to indicate this fact.

Received December 9, 2020; revised February 25, 2021; accepted June 4, 2021; published first August 13, 2021.

4. Suzuki Y, Nakabayashi Y, Takahashi R. Ubiquitin-protein ligase activity of Xlinked inhibitor of apoptosis protein promotes proteasomal degradation of caspase-3 and enhances its anti-apoptotic effect in Fas-induced cell death. Proc Natl Acad Sci U S A 2001;98:8662-7.

5. Bertrand MJ, Milutinovic S, Dickson KM, Ho WC, Boudreault A, Durkin J, et al. cIAP1 and cIAP2 facilitate cancer cell survival by functioning as E3 ligases that promote RIP1 ubiquitination. Mol Cell 2008;30:689-700.

6. Micheau O, Tschopp J. Induction of TNF receptor I-mediated apoptosis via two sequential signaling complexes. Cell 2003;114:181-90. 
7. Sun XS, Tao Y, Le Tourneau C, Pointreau Y, Sire C, Kaminsky MC, et al. Debio 1143 and high-dose cisplatin chemoradiotherapy in high-risk locoregionally advanced squamous cell carcinoma of the head and neck: a double-blind, multicentre, randomised, phase 2 study. Lancet Oncol 2020;21:1173-87.

8. Johnson CN, Ahn JS, Buck IM, Chiarparin E, Day JEH, Hopkins A, et al. A fragment-derived clinical candidate for antagonism of X-linked and cellular inhibitor of apoptosis proteins: 1-(6-[(4-Fluorophenyl)methyl]-5-(hydroxymethyl)-3,3-dimethyl-1 H, 2 H, 3 H-pyrrolo[3, 2- b]pyridin-1-yl)-2-[(2 R, 5 R)-5-methyl-2-([(3R)-3-methylmorpholin-4-yl]methyl)piperazin-1-yl]ethan1-one (ASTX660). J Med Chem 2018;61:7314-29.

9. Mita MM, LoRusso PM, Papadopoulos KP, Gordon MS, Mita AC, Ferraldeschi $\mathrm{R}$, et al. A phase 1 study of ASTX660, an antagonist of inhibitors of apoptosis proteins, in adults with advanced cancers or lymphoma. Clin Cancer Res 2020; 26:2819-26.

10. Marisa L, de Reynies A, Duval A, Selves J, Gaub MP, Vescovo L, et al. Gene expression classification of colon cancer into molecular subtypes: characterization, validation, and prognostic value. PLoS Med 2013;10:e1001453.

11. Langfelder P, Horvath S. WGCNA: an R package for weighted correlation network analysis. BMC Bioinformatics 2008;9:559.

12. Aran $\mathrm{D}, \mathrm{Hu} \mathrm{Z}$, Butte AJ. xCell: digitally portraying the tissue cellular heterogeneity landscape. Genome Biol 2017;18:220.

13. Reich M, Liefeld T, Gould J, Lerner J, Tamayo P, Mesirov JP. GenePattern 2.0. Nat Genet 2006;38:500-1.

14. Liberzon A, Birger C, Thorvaldsdottir H, Ghandi M, Mesirov JP, Tamayo P. The Molecular Signatures Database (MSigDB) hallmark gene set collection. Cell Syst 2015;1:417-25

15. Barretina J, Caponigro G, Stransky N, Venkatesan K, Margolin AA, Kim S, et al. The cancer cell line encyclopedia enables predictive modelling of anticancer drug sensitivity. Nature 2012;483:603-7.

16. Schwitalla S, Fingerle AA, Cammareri P, Nebelsiek T, Goktuna SI, Ziegler PK, et al. Intestinal tumorigenesis initiated by dedifferentiation and acquisition of stem-cell-like properties. Cell 2013;152:25-38.

17. Cammareri P, Vincent DF, Hodder MC, Ridgway RA, Murgia C, Nobis M, et al. TGFbeta pathway limits dedifferentiation following WNT and MAPK pathway activation to suppress intestinal tumourigenesis. Cell Death Differ 2017;24: 1681-93.

18. Crawford N, Stasik I, Holohan C, Majkut J, McGrath M, Johnston PG, et al. SAHA overcomes FLIP-mediated inhibition of SMAC mimetic-induced apoptosis in mesothelioma. Cell Death Dis 2013;4:e733.

19. Kerr E, Holohan C, McLaughlin KM, Majkut J, Dolan S, Redmond K, et al Identification of an acetylation-dependant Ku70/FLIP complex that regulates FLIP expression and HDAC inhibitor-induced apoptosis. Cell Death Differ 2012;19:1317-27

20. Lees A, McIntyre AJ, Crawford NT, Falcone F, McCann C, Holohan C, et al. The pseudo-caspase FLIP(L) regulates cell fate following p53 activation. Proc Natl Acad Sci U S A 2020;117:17808-19.

21. McCann C, Crawford N, Majkut J, Holohan C, Armstrong CWD, Maxwell PJ, et al. Cytoplasmic FLIP(S) and nuclear FLIP(L) mediate resistance of castrateresistant prostate cancer to apoptosis induced by IAP antagonists. Cell Death Dis 2018;9:1081.

22. Parameswaran N, Patial S. Tumor necrosis factor-alpha signaling in macrophages. Crit Rev Eukaryot Gene Expr 2010;20:87-103.

23. Varfolomeev E, Blankenship JW, Wayson SM, Fedorova AV, Kayagaki N, Garg $\mathrm{P}$, et al. IAP antagonists induce autoubiquitination of c-IAPs, NF-kappaB activation, and TNFalpha-dependent apoptosis. Cell 2007;131:669-81.

24. Feltham R, Bettjeman B, Budhidarmo R, Mace PD, Shirley S, Condon SM, et al. Smac mimetics activate the E3 ligase activity of cIAP1 protein by promoting RING domain dimerization. J Biol Chem 2011;286:17015-28.

25. Wong WW, Vince JE, Lalaoui N, Lawlor KE, Chau D, Bankovacki A, et al. cIAPs and XIAP regulate myelopoiesis through cytokine production in an RIPK1- and RIPK3-dependent manner. Blood 2014;123:2562-72.

26. Majkut J, Sgobba M, Holohan C, Crawford N, Logan AE, Kerr E, et al. Differential affinity of FLIP and procaspase 8 for FADD's DED binding surfaces regulates DISC assembly. Nat Commun 2014;5:3350.

27. Humphreys LM, Fox JP, Higgins CA, Majkut J, Sessler T, McLaughlin K, et al. A revised model of TRAIL-R2 DISC assembly explains how FLIP(L) can inhibit or promote apoptosis. EMBO Rep 2020;21:e49254.

28. Muhlethaler-Mottet A, Flahaut M, Bourloud KB, Nardou K, Coulon A, Liberman J, et al. Individual caspase-10 isoforms play distinct and opposing roles in the initiation of death receptor-mediated tumour cell apoptosis. Cell Death Dis 2011;2:e125.
29. Horn S, Hughes MA, Schilling R, Sticht C, Tenev T, Ploesser M, et al. Caspase-10 negatively regulates Caspase-8-mediated cell death, switching the response to CD95L in favor of NF-kappaB activation and cell survival. Cell Rep 2017; 19:785-97.

30. Shiffman M, Freilich B, Vuppalanchi R, Watt K, Chan JL, Spada A, et al. Randomised clinical trial: emricasan versus placebo significantly decreases ALT and caspase $3 / 7$ activation in subjects with non-alcoholic fatty liver disease. Aliment Pharmacol Ther 2019;49:64-73.

31. Krajewska M, Kim H, Kim C, Kang H, Welsh K, Matsuzawa S, et al. Analysis of apoptosis protein expression in early-stage colorectal cancer suggests opportunities for new prognostic biomarkers. Clin Cancer Res 2005;11:5451-61.

32. Flanagan L, Kehoe J, Fay J, Bacon O, Lindner AU, Kay EW, et al. High levels of X-linked Inhibitor-of-Apoptosis Protein (XIAP) are indicative of radio chemotherapy resistance in rectal cancer. Radiat Oncol 2015;10:131.

33. Xiao R, Allen CT, Tran L, Patel P, Park SJ, Chen Z, et al. Antagonist of cIAP1/2 and XIAP enhances anti-tumor immunity when combined with radiation and PD-1 blockade in a syngeneic model of head and neck cancer. Oncoimmunology 2018;7:e1471440

34. Xiao R, An Y, Ye W, Derakhshan A, Cheng H, Yang X, et al. Dual antagonist of cIAP/XIAP ASTX660 sensitizes HPV(-) and $\mathrm{HPV}(+)$ head and neck cancers to TNFalpha, TRAIL, and radiation therapy. Clin Cancer Res 2019; 25:6463-74.

35. Mlecnik B, Bindea G, Angell HK, Maby P, Angelova M, Tougeron D, et al. Integrative analyses of colorectal cancer show immunoscore is a stronger predictor of patient survival than microsatellite instability. Immunity 2016; 44:698-711.

36. Wang CY, Mayo MW, Korneluk RG, Goeddel DV, Baldwin AS Jr. NF-kappaB antiapoptosis: induction of TRAF1 and TRAF2 and c-IAP1 and c-IAP2 to suppress caspase-8 activation. Science 1998;281:1680-3.

37. Feoktistova M, Geserick P, Kellert B, Dimitrova DP, Langlais C, Hupe M, et al. cIAPs block Ripoptosome formation, a RIP1/caspase- 8 containing intracellular cell death complex differentially regulated by cFLIP isoforms. Mol Cell 2011;43: 449-63.

38. Lin Y, Devin A, Rodriguez Y, Liu ZG. Cleavage of the death domain kinase RIP by caspase-8 prompts TNF-induced apoptosis. Genes Dev 1999;13:2514-26.

39. Qin J, Wen B, Liang Y, Yu W, Li H. Histone modifications and their role in colorectal cancer (Review). Pathol Oncol Res 2020;26:2023-33.

40. Featherstone $\mathrm{C}$, Jackson $\mathrm{SP}$. $\mathrm{Ku}$, a DNA repair protein with multiple cellular functions? Mutat Res 1999;434:3-15.

41. Chen M, Orozco A, Spencer DM, Wang J. Activation of initiator caspases through a stable dimeric intermediate. J Biol Chem 2002;277:50761-7.

42. He S, Wang L, Miao L, Wang T, Du F, Zhao L, et al. Receptor interacting protein kinase-3 determines cellular necrotic response to TNF-alpha. Cell 2009;137: 1100-11.

43. Cai Z, Jitkaew S, Zhao J, Chiang HC, Choksi S, Liu J, et al. Plasma membrane translocation of trimerized MLKL protein is required for TNF-induced necroptosis. Nat Cell Biol 2014;16:55-65.

44. Aaes TL, Kaczmarek A, Delvaeye T, De Craene B, De Koker S, Heyndrickx L, et al. Vaccination with necroptotic cancer cells induces efficient anti-tumor immunity. Cell Rep 2016;15:274-87.

45. Yatim N, Jusforgues-Saklani H, Orozco S, Schulz O, Barreira da Silva R, Reis e Sousa C, et al. RIPK1 and NF-kappaB signaling in dying cells determines crosspriming of CD8(+) T cells. Science 2015;350:328-34.

46. Moriwaki K, Bertin J, Gough PJ, Orlowski GM, Chan FK. Differential roles of RIPK1 and RIPK3 in TNF-induced necroptosis and chemotherapeutic agentinduced cell death. Cell Death Dis 2015;6:e1636.

47. Conev NV, Dimitrova EG, Bogdanova MK, Kashlov YK, Chaushev BG, Radanova MA, et al. RIPK3 expression as a potential predictive and prognostic marker in metastatic colon cancer. Clin Invest Med 2019;42:E31-E38.

48. Najafov A, Zervantonakis IK, Mookhtiar AK, Greninger P, March RJ, Egan RK, et al. BRAF and AXL oncogenes drive RIPK3 expression loss in cancer. PLoS Biol 2018;16:e2005756.

49. Brumatti G, Ma C, Lalaoui N, Nguyen NY, Navarro M, Tanzer MC, et al. The caspase- 8 inhibitor emricasan combines with the SMAC mimetic birinapant to induce necroptosis and treat acute myeloid leukemia. Sci Transl Med 2016;8: $339 \mathrm{ra} 369$.

50. Ye W, Gunti S, Allen CT, Hong Y, Clavijo PE, Van Waes C, et al. ASTX660, an antagonist of cIAP1/2 and XIAP, increases antigen processing machinery and can enhance radiation-induced immunogenic cell death in preclinical models of head and neck cancer. Oncoimmunology 2020;9:1710398. 


\section{Molecular Cancer Therapeutics}

\section{Clinical Positioning of the IAP Antagonist Tolinapant (ASTX660) in Colorectal Cancer}

Nyree Crawford, Katie J. Stott, Tamas Sessler, et al.

Mol Cancer Ther Published OnlineFirst August 13, 2021.

Updated version Access the most recent version of this article at: doi:10.1158/1535-7163.MCT-20-1050

Supplementary Access the most recent supplemental material at:

Material http://mct.aacrjournals.org/content/suppl/2021/06/10/1535-7163.MCT-20-1050.DC1

E-mail alerts Sign up to receive free email-alerts related to this article or journal.

Reprints and To order reprints of this article or to subscribe to the journal, contact the AACR Publications Subscriptions Department at pubs@aacr.org.

Permissions To request permission to re-use all or part of this article, use this link http://mct.aacrjournals.org/content/early/2021/08/13/1535-7163.MCT-20-1050.

Click on "Request Permissions" which will take you to the Copyright Clearance Center's (CCC)

Rightslink site. 